\title{
Analysis of the Mechanism of Political Cost in the Complex Environmental Governance System
}

\author{
Xintao Li $\mathbb{D},{ }^{1,2}$ Tongshun Cheng $\mathbb{D},^{1,2}$ Zaisheng Zhang $\mathbb{D},^{3}$ and Li Zhao $\mathbb{D}^{1}$ \\ ${ }^{1}$ Zhou Enlai School of Government, Nankai University, Tianjin 300350, China \\ ${ }^{2}$ Chinese Government and Policy Joint Research Center, Nankai University, Tianjin 300350, China \\ ${ }^{3}$ College of Management and Economics, Tianjin University, Tianjin 300072, China \\ Correspondence should be addressed to Li Zhao; zhaoli@nankai.edu.cn
}

Received 22 May 2020; Revised 27 November 2021; Accepted 4 December 2021; Published 23 February 2022

Academic Editor: Ning Cai

Copyright (c) 2022 Xintao Li et al. This is an open access article distributed under the Creative Commons Attribution License, which permits unrestricted use, distribution, and reproduction in any medium, provided the original work is properly cited.

\begin{abstract}
The emergence of conflicts between environmental safety incidents and protection rights generates sizeable political costs, which endangers the legitimacy of the government as well as political security and stability. This article further examines the role of political costs in environmental issues. First, political costs in relation to environmental issues are defined. An equilibrium strategic analysis is then presented using an evolutionary game model in which the strategic behavioral choices of government, enterprises, and citizens are investigated by embedding political costs in the environmental governance system. Furthermore, the small-signal model was innovatively applied to simulate and analyze the stability of political costs under different equilibrium strategies in the system. The results show the following. (1) Pubic behavior and government are the dominant factors that impact stability and instability, respectively. Public behavior is the core element that affects political cost consumption. (2) When political costs are extremely depleted, the public will neglect economic interests, turn toward environmental interests, and choose the negative participation strategy, which destabilizes the system. (3) The political cost signal at the optimal equilibrium point not only warns the government not to take the desperate action of concealing information asymmetry but also allows the government to let go of its hands to deal with the environmental issues. Corresponding policy recommendations are proposed.
\end{abstract}

\section{Introduction}

Considering the advancement of industrialization, environmental pollution is becoming increasingly more serious due to rapid economic development and urbanization [1]. Between 2003 and 2021, there has been an increase in the number of environmental "mass incidents" caused by environmental pollution, environmental facilities, and many other issues. In particular, three widespread "Not in My Backyard (NIMBY) Movement" incidents occurred in China in 2012. Anti-pollution protests were carried out in Qidong, Jiangsu Province, the Molybdenum Copper Project protest took place in Shifang County, Sichuan Province, and the Anti-PX Project demonstration took place in Pengze, Jiangxi Province [2]. In recent years, environmental mass incidents have attracted widespread attention among people from all walks of life, including scholars from various fields, due to the frequency with which they occur and the substantial harmful effects that follow [3]. It is reported that only $35.8 \%$ of 338 Chinese cities at the prefectural level or higher had satisfied the air quality standards based on the survey data of the Ministry of Ecology and Environment. Moreover, the average number of days that exceed the standard for good weather is $20.7 \%$, and only seven cities satisfied the standard for good weather every day [4]. However, local government departments tend to ignore the consumption of intangible resources as they are influenced by concepts such as "GDP competition," "promotion championship," and "economy and employment first" [5]. In addition, there is an imbalance in terms of the distribution of costs and benefits, which can be attributed to defects in the environmental system, implementation errors, the conflict that exists between economic development and environmental protection, and the increasing conflict that is encountered between 
environmental safety incidents and environmental protection [6]. If this situation continues, the impact will be evident across many different domains, including social stability, government credibility, and public satisfaction. Ultimately, this will result in a sizeable loss of tangible and intangible resources. The government has to increase various resource inputs to achieve its environmental governance goals. Among them, the consumption of political resources constitutes the political cost of environmental problems. The political cost of environmental issues includes the political resources consumed by the government as well as the political costs borne by society, organizations, or others in the process of exercising political power and taking political actions in order to achieve environmental governance and meet the public demand for a better living environment.

The excessive consumption of political costs will endanger the legitimacy of the government as well as political security and stability, thereby forcing the government to passively respond to various problems arising in the process of environmental protection and environmental governance through institutionalized means, under the condition of " government lagging perception" to curb the crisis. In addition, with the development of political democratization and the increase in public awareness of environmental rights and participation, the public's understanding of political costs has gradually changed from abstraction, absoluteness, and passiveness to materialization, reality, and initiative. Internationally, some countries such as the United States and Japan have neglected political costs and generated serious political consequences in environmental governance, which has triggered larger mass incidents and economic crises and led to the loss of substantial political resources [7]. The political legitimacy and political ecology have caused the public to lose confidence in the ruling party and brought about a decline in its level of support, which has left the public with a"sequelae" of"political indifference." Political costs are comparable to the natural ecology. Once it is severely damaged, the restoration will have to pay a huge price, and it is even more difficult to"restore as before." The political impact on various interest groups, due to wasted political resources, will increase the political costs of environmental issues. Excessive political costs will pose a threat to the legitimacy of the government and furthermore jeopardize political security and stability. The ecological environment is a major political issue in terms of the mission and purpose of the ruling party and the government [8]. However, at present, academic research on environmental governance costs mainly focuses on economic costs, and few studies have been conducted to examine political costs [9]. Therefore, one of the most important issues that the government must confront and resolve is related to the role of political costs of environmental issues in the complex governance system. It is also necessary to study this issue systematically from both theoretical and mathematical perspectives.

This paper took the political cost of environmental issues as the research object and investigated the evolutionary mechanism of the political cost of environmental issues by developing a theoretical model of the relationship. First, this paper establishes the payment matrix of environmental governance entities and analyzes its evolution equilibrium. Next, a small-signal model was set. Finally, a numerical simulation of the effect of political costs was carried out. This paper aims to identify the chain evolutionary mechanism of the political cost of environmental problems, its role in the environmental governance system, and the corresponding governance strategy. Moreover, this will be an important step in measuring the political cost of environmental problems [10]. This paper can help to improve the efficiency of environmental governance carried out by the government, realize the coordinated development of the social economy and the ecological environment, resolve local crises, and maintain the country's political security and stability. It is of great theoretical significance and is of practical value as it contributes to broadening the research perspective that is adopted to explore environmental issues.

\section{The Definition and Literature Review}

\subsection{The Definition of the Political Cost of Environmental Issues.} The issue of environmental governance has become a political issue and an important part of the political life of many countries. The introduction of political science, public administration, and economics in environmental governance is conducive to broadening the connotation and extension of environmental governance, which can help the government to determine an effective and precise path with respect to environmental management. In 1844, French engineer J. Dupuy proposed that governments should adopt the idea of cost-utility analysis in relation to administrative execution and the "Utility Measurement of Public Works." With the increasing diversity and complexity of public affairs, the importance of the cost of governance in the government is a concept that has emerged repeatedly. In his trilogy of political systems theory, American scholar David proposed that for a political system to function properly, it must have some resources to serve as a driving force and foundation. This was also the first time that political scholars introduced the concept of political resources [11]. Harold and Long subsequently continued to deepen the interpretation of the concept of political resources, arguing that elements such as the institutional mechanisms of politics, political organization and culture, and external governance structures of politics are a political means to influence political objects that can be constantly consumed and lost [12, 13]. The government needs to have and consume certain resources (e.g., the means and methods used by political entities to influence and act on political objects), which constitute political resources, in order to exercise political power and governance behavior, which thus reflects the value of its existence and achieves its governance goals [14]. The cost of government governance refers to the sum of various human, material, and financial resources invested and generated by the government in order to obtain governance performance. It can be divided into "tangible resources" (e.g., economic resources), which are materially consumed, and "intangible resources" (e.g., political resources), which reflect the authority and legitimacy of the government. Due to the hidden 
characteristics of intangible resources, they are often ignored by the government [15]. In addition, intangible resources also exist objectively and are constantly used and consumed by the government or political parties within the context of their political activities, examples of which include organizational resources, the concept of democracy, and governance advocated by the government, in the organizational structure of government [16]. Therefore, a country, government, or political party that values and effectively uses intangible resources will appear more stable in terms of its legitimacy base and political security. Political science scholars took this opportunity to define the connotation of political costs, arguing that society and the administrative system will consume resources, which leads to administrative inefficiency, public policy failure, or other problems and thereby brings about a decrease in public support and identification with the government, government legitimacy, and political authority. The political resources consumed are termed political costs $[17,18]$.

In recent years, the issue of environmental governance has become important in the political system. In its capacity as a governor, the government not only needs to provide environmental public goods but also needs to use environmental governance resources scientifically to maximize the supply of environmental public goods. The government has invested sizeable financial, human, and material resources to manage the environment and address public incidents caused by environmental problems, which means that many economic, political, and social resources are needed. Myers pointed out that "ecological crises and environmental security are about the political stability of the government and are a fundamental variable in the issue of political stability and social security" [19]. Under the coercive character of the governmental system, institutional discrimination, the uneven distribution of governmental public goods supply and benefits, and unfair procedures will trigger protests by various interest entities. For example, during the protests that took place against waste incineration power projects in Asuwei, Beijing, in 2009 and Xiantao, Zhejiang, in 2016, and the explosion of a chemical plant in Xiangshui, Jiangsu, in 2019, the public first defended their rights and expressed their interests by reasonably expressing their demands. However, due to mishandling by local governments and the low governance capacity of some officials, it was not possible to effectively address the public's environmental demands. As such, some people started to defend their rights by illegal and irregular means. Therefore, the number of illegal petitions and lawsuits significantly increased, and this situation is highly likely to result in an outbreak of environmental mass incidents. The interests of the public and other governance entities have led to the selective allocation of political resources, which means that neglect in the area of political costs is constantly visible and expressed by public demands or the occurrence of protest events [20].

Based on the above analysis, the political costs of environmental issues can be understood as the political resources that are consumed by the government as well as the political costs that are borne by society, organizations, or others in the process of exercising political power and taking political measures in order to achieve environmental governance and meet the public demand for a better living environment. Political costs not only refer to intangible and scarce resources which are difficult to acquire and accumulate, but they also belong to a special type of cost, which means that they are difficult to repair once damaged. Specifically, political costs contain the following elements. (1) In environmental governance, local governments use various institutional political resources, such as institutional systems and policies and regulations, to regulate and constrain the relationships and behaviors among various governance entities. These laws and policies belong to the institutional system of environmental governance, and the institutional political costs of the government to achieve the governance of environmental problems and environmental sustainability [21]. (2) The implementation of policies and systems promulgated by the nation regarding the governance of environmental issues requires the participation and implementation of the government [22], social organizations, and relevant staff. These governance organizations and staff together form the system of political organization that guarantees the effective functioning of environmental governance, which is the organizational political cost of environmental issues. (3) The political system must contain a certain value cognition system, since the modern governance is a political behavior guided by certain value concepts and cognition. This value cognition system is referred to as a socially perceptive political cost, which not only includes publicity and education resources that are necessary for the long-term behavior of social entities to produce a political identity, but also the government vis-à-vis the propaganda and education system that is designed to enable the social public to form ideals and beliefs, moral codes, legal consciousness and a social mentality that are compatible [23]. (4) The current environmental pollution management problems and the continuous occurrence of environmental mass incidents have a negative impact on public rights, property, mentality, and public political perceptions and attitudes, while public satisfaction, political identity, and political trust are also expressed through the public's political behaviors. At the same time, the management of environmental problems and environmental mass events is a complex and long-term systemic project that requires long and uninterrupted public participation and support and therefore also includes mass behavioral political costs [24].

2.2. Literature Review. Evolutionary game theory (EGT) is a scientific reasoning method that is commonly employed by scholars to solve environmental problems and analyze mass events. It posits that a player cannot make a strategic adjustment quickly in response to changes in the external environment and emphasizes the dynamic process of the game under finite rational decisions. This theory can be applied to analyze the learning selection and strategy adjustment process of finite rational game parties, and its starting point is to use the most effective ways to maximize the satisfaction of all preferences of each interest subject 
(e.g., government, public, and enterprises). It simplifies dynamic and complex problems to a manageable degree and facilitates rational strategic choices that are in each rational economist's interest by identifying the key variables of the behavioral strategy choice process among stakeholders and the steady state of the game system, which eventually converges to local stability $[25,26]$. Environmental governance is an evolving, open, intrinsically coupled, nonlinear, and complex system, in which the internal governance structure of government departments, enterprises, the public, and other governance entities occurs in a complex multilevel interaction, such that each level of a relationship is distributed in a chain and works in tandem with others to assist the overall role. Environmental governance systems are closely related to their surroundings. The constant interactions between them mean that the systems evolve from low to high, from simple to complex, and from functional to structural. At present, increasingly more research studies are trying to use the evolutionary game approach to solve environmental governance issues within the context of multiple entities. In 1978, Taylor and Jonker analyzed the inherent system dynamics between the equilibrium of evolutionary games from the perspective of system dynamics and pointed out the existence of dynamics between the two sides of the evolutionary game. Chen et al. discussed the positive role and significance of public participation in integrated water resources management using a game theory approach [27]. Lu and Chen analyzed the evolutionary process of decision making between the local government and central government, among local governments, and between local governments and polluting enterprises from the perspective of evolutionary game theory, respectively [28]. Sheng et al. used the evolutionary game model to clarify the subject game relationship in respect to rural water environmental management actions by analyzing the evolutionary process of the three game entities: local government, enterprises, and farmers [29]. Matjaz and Attila analyzed the evolutionary formation of a compensation mechanism between upstream and downstream government groups in transboundary pollution management by using a singlepopulation evolutionary model and a two-population evolutionary model, respectively [30]. By constructing a centrallocal-public tripartite noncooperative evolutionary game model, Chu et al. found that local government environmental regulation strategies influence public third-party supervision and could completely replace the central government's administrative control role, which was helpful in solving the "middle blockage" problem of the local government in regard to air pollution prevention [31]. To provide a direct means of interpreting the whole scenario of the conflict that exists in the area of environmental mass issues and to analyze the game of interests among governance entities, researchers have applied the evolutionary game theory to the game relationship between government, the public, and enterprises. This is consistent with the scenario in which the interest entities in environmental pollution governance. None of the game parties know each other's willingness and capability to implement environmental pollution governance. Moreover, the degree of rationality of the game parties is limited, and the decisionmaking behavior is based on the premise of limited rationality. Due to the limitations of traditional game theory, it is more practical to use evolutionary game theory to study the game behavior of each interest subject in the system of environmental pollution control.

The small-signal model linearizes the nonlinear system, and the characteristic curve in a small range of the system is approximately replaced by a straight line $[32,33]$. For example, the relationship between point $M$ and point $D$ is nonlinear, but the relationship between a disturbance with a small duty cycle and a gain variation is linear in a small area near its static working point $M$. Therefore, within this small area (a certain static working point), the linear analysis method is used to analyze the system. This simplifies the system and facilitates an analysis of dynamic stability characteristics and the identification of unstable elements, which ensures the normal operation of the system or a reduction in any negative effects. As such, issues encountered in previous studies with respect to the algorithm of direct assignment simulation after the equilibrium analysis are addressed, which thus improves the analysis speed [34]. Stability is paramount to ensure the operation of the system, that is, its stable operation in a steady state, and for transient characteristics such as system recovery after failure [35]. However, the existence of time delays makes the stability analysis of the system more difficult. In recent years, many researchers have used the small-signal model theory in studies related to environmental ecology, traffic signals, neural networks, power circuits, digital signal processing, and other research fields. Umamaheswari et al. established a simple small-signal model for a traffic signaling system, which contained the most basic intrinsic parameters [36]. Antoine et al. used support vector regression (SVR) technology to study the small-signal model of a power supply circuit and determined the optimal value of components according to the results of small-signal measurement [37]. Zhu and Brunodeveloped an efficient neural network smallsignal parameter extraction method with MATLAB, which reduced the influence of system test errors and parameter error accumulation [38]. The complex system of environmental governance is a nonlinear system. Although the attributes of its internal elements are different, there is a relationship that is characterized by mutual influence and cooperation. Meanwhile, interference in the system is observed; sometimes, some interference factors or events that managers delay in processing, and then have an effect on the governance system and the original scheme, even negative effects $[39,40]$. In environmental emergencies, in particular, such as a chemical plant explosion, the small-signal model enables managers to interfere with social organizations and the public; quickly identify and evaluate the factors that interfere with the stability of the system in a short time; devise an adjustment scheme that causes the least disturbance to the system; and formulate an optimal countermeasure to manage emergencies on the basis of the original emergency scheme [41], so that the system can quickly resume normal operations under the condition of minimizing the governance cost. The shortcomings of the 
existing game theory method for environmental system issues are also remedied.

In recent years, the researchers focused on exploring how the pollution crisis could be dealt with effectively, how pollution can be prevented, and how the environment can be improved. The first issue relates to an analysis of the causes of pollution. Academic research generally aims to analyze the inherent reasons for environmental pollution problems, such as the public's awareness and participation in pollution control, the different interests of various governance entities, and the traditional ethical norms of rural communities, all of which affect the level of environmental pollution control. Therefore, environmental issues in the region should be considered with social perceptions and other states [42-44]. The second issue relates to environmental governance approaches. Researchers believe that social organizations play a very important role in the process of environmental governance. In the meantime, they also believe that the current environmental emergency system is somewhat weak and the management system is imperfect. In addition, there is a lack in respect to the technical support system. Good governance in this area can only be achieved by developing a multicentered model of environmental governance. An effective and comprehensive ecological improvement can be brought about by encouraging coordination among inter-regional governments. Furthermore, the environmental governance carried out by local officials can be improved using a performance incentive mechanism (promotion). Moreover, environmental governance should be subject to audits and policy evaluations, which should be actively carried out throughout the whole process, and an emphasis should be placed on the role of rural elites in environmental governance. Last, but not least, environmental problems should be resolved by adopting a perspective that focuses on improving the government's ability to carry out ecological environmental governance [45-48]. The third issue relates to the research methods of environmental governance. Researchers optimize current environmental governance policies and measures according to the level of coordination and the relationships that exist among the multiple parties engaged in environmental governance, such as the government, society, enterprises, and the public. The commonly used analytic models include the following: the coordination model, social network model, evolutionary game model, cooperative game model, and differential game model [49-52]. Finally, researchers are also actively involved in exploring environmental risk governance. Scheffran and Hannon stated that it is essential that relevant institutions adopt effective, timely, and comprehensive communication methods in the area of environmental governance in order to respond to the emergence of a situation that poses an environmental risk [53]. Rajesh constructed an interpretative framework for environmental risk [54]. Furthermore, Yamashita discussed the importance of communication mechanisms between the government and the public in respect to environmental risk governance [55]. In addition, Nakazawa et al. suggested that the government should establish a two-way communication mechanism and a perfect risk assessment mechanism with the public [56-58].
Moreover, the transparency of various environmental assessments should be enhanced, including public meetings and website voting, so as to reduce the negative cost of "NIMBY" or "Not in My Backyard" effects incurred by society.

Above all, many studies have examined environmental issues and carried out in-depth discussion about the governance mechanism and path, the cost of governance, the economic cost of environmental issues, and the regulatory issues associated with environmental governance. The optimal allocation of governmental political resources is a game process in which stakeholders reach an agreement to form a Pareto optimum [15]. However, it is evident that little consideration has been given to the political cost of environmental issues, and there is a lack of understanding regarding its significance. Moreover, few quantitative analyses have been conducted. The analysis of the key elements of political costs in the environmental governance system has not been further studied, and research on the stability of political costs in relation to the environmental governance system is relatively rare. Evolutionary game theory is a scientific reasoning method that is commonly used in the process of solving environmental problems and analyzing group events in academic circles. This method uses the most effective method to satisfy all of the preferences of the relevant parties to the greatest possible extent. Therefore, it can simplify dynamic and complex problems within a controllable level, so as to encourage each rational economic person to select a rational strategy based on their interests. This paper introduces complex systems theory into the interpretative framework of the political cost of environmental issues, which aims to explore how the game relationship of the vested behavior of governance entities impacts upon the political cost of environmental governance. Governance entities include the government, enterprises, and the public. Therefore, this allows the government to curb the rigid growth that is brought about by the distribution of nondifferentiated environmental public products. Furthermore, the efficiency of environmental governance can be improved, and it is important to attend to and thoroughly study the role of political costs in relation to Xujie environmental issues.

\section{Basic Assumptions of the Game Players}

From the perspective of"public choice theory," the government, as a rational economist and agent, has to provide the necessary ecological public goods to the public. It will continuously incur various"transaction costs" in the process of governance, so that it is not able to"take care" of enterprises and other interests fairly. In turn, the various interest players will use diverse channels to influence the formulation of environmental policies, so that they eventually reach equilibrium. If there are other forms of organization that have lower transaction costs than the government, and these do not involve equalization of provision, the interests may seek other forms of organization, resulting in reduced political legitimacy of the government [59]. At the same time, the expression of interests 
and demands of various interest entities may interfere with the optimality of policies, which can cause a deviation in the choice of environmental policies and result in the consumption of limited political resources in environmental governance. For example, a warehouse fire occurred at the Sandoz chemical plant in Basel, Switzerland, and the managers quickly identified and assessed the disturbance risk events under the situation of public interference. They investigated optimal countermeasures and devised solutions addressing the emergency based on the original contingency plan. In turn, the system could be restored to normal operations as soon as possible with minimal governance costs [60]. Marten Alex posited that externalities exist due to the difference between the marginal private net production value and marginal social net production value [61]. If the two are equal, this means that the resource allocation is optimal; otherwise, there is an externality. If the marginal social net production value is greater than the marginal private net production value, this indicates that others gain from it, which is beneficial for society; conversely, it means that some people lose as a result, which has a negative impact on society. This corresponds to the definition of positive and negative externalities. It is the existence of the externality that makes it impossible to maximize social welfare by relying on free competition in the environment.

Since the process of environmental pollution control involves too many entities of interest, there is too much conflict of interest between entities, and environmental pollution control itself has a high degree of externalities, and in order to ensure that their interests are not damaged, the game between entities of interest is constant. This means that the strategies cannot be thoroughly and effectively implemented, which thus affects the effectiveness of environmental pollution control. For example, maximizing their interests, enterprises transfer the cost of pollution treatment to society, which leads to the misuse of environmental resources and causes externalities, such as environmental pollution. In addition, the environment is a public good, and its negative externality will bring about a"market failure" in which the market is unable to allocate resources effectively. The commons tragedy (the nonexclusivity and noncompetitiveness of the environment allow enterprises and other polluters to use it without restraint) can only be avoided by means of reasonable and effective allocation by the government. Although the process of environmental pollution control will inevitably have a dampening effect on economic growth, environmental protection is imperative for the pursuit of sustainable development, as well as for the safety of public and social stability. The government should subsidize production that has a favorable impact on society (i.e., production that is associated with positive externalities) and tax production that has a negative impact on society (i.e., production that is associated with negative externalities) in order to internalize the externalities. Compared with the burden borne by the public as a result of externalities associated with environmental pollution, the purpose of public supervision in the area of environmental governance is not to offer rewards but to increase public participation as a means of effectively suppressing the negative externalities of environmental pollution as well as to curb the tendency of local governments to exchange environmental pollution for political performance and reduce the loss of political costs. Supervision, punishment, altruism, and reciprocity are observed among the three game interested parties: government, enterprise, and the public, which is consistent with the evolutionary game theory (as shown in Figure 1). The basic assumptions are as follows. All three game entities show the basic characteristics of the Homo economicus assumption: they always consider cost and benefit issues and pursue the maximization of their interests. At the same time, the government is rational and chooses behavioral strategies according to preferences in the process of development of the game events.

\section{Construction of the Game Model and Evolutionary Equilibrium Analysis}

4.1. Construction of the Game Model. In environmental governance, the government, enterprises, and the public interact with each other, and the interactions determine the evolution of the game. According to the assumption of the rational economic man, the basis of strategy selection, for of all kinds of entities, is based on maximizing their interests. For this reason, with the help of the payment matrix, the adaptation analysis of the participating entities is performed, and then the single-population evolutionary stable strategy of the system is constructed by solving the replicated dynamic equations.

(1) In this stage of the evolutionary game theory, the enterprise is an important game player, and its behavior is in line with the hypothesis of the rational economic man. In terms of cost, the enterprise's cost input is the environmental protection technology and reform input cost $C_{3}$ in this stage. There is also the environmental tax paid to the government $\left(F_{1}\right.$ is the environmental tax paid when the enterprise is compliant; $F_{2}$ is the environmental tax paid when the enterprise is noncompliant; and $\theta$ is the percentage of tax paid to the government on the enterprise's income). In terms of revenue, in addition to the enterprise's production revenue (the main business income when the enterprise is compliant is $R_{1}$; the main business income when the enterprise is noncompliant is $R_{2}$ ), the enterprise's income also includes special transfer funds invested by the government in the area of environmental protection and technological transformation $T$ and the public's reputation evaluation $E_{2}$. In line with the most rational economic man, the enterprise will strive to maximize its interests [62]. Therefore, enterprises will aim to achieve the lowest production cost in the early stage of the game. At this time, they will not pay attention to addressing issues related to environmental pollution, and some enterprises will even adopt an unlawful production strategy. However, enterprises will be forced to comply with the government's regulations. When the government 


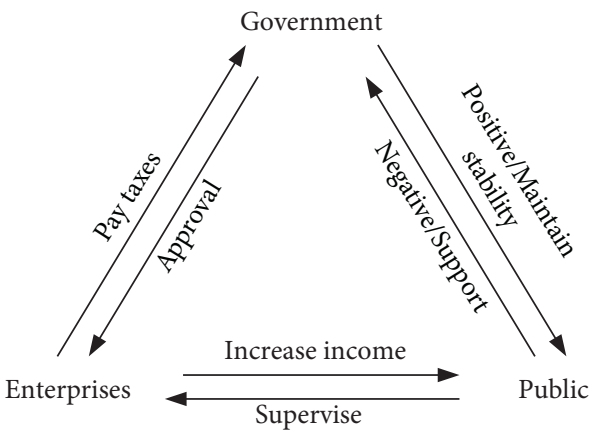

Figure 1: Theoretical model of the relationship between the government, enterprises, and the public with respect to environmental governance.

actively manages environmental problems, enterprises will adopt a production strategy of compliance (i.e., the political penalties for their noncompliance $P$ ), particularly when there is public participation in this area. The economic loss to the enterprise caused by the loss of environmental quality is represented by $L_{2}$. All of these actions generate conflicts of interest among all of the parties, which results in an unbalanced distribution of interests.

Therefore, enterprises will adopt two kinds of behavioral strategies (i.e., compliance and violation) in this stage of the evolutionary game. The compliance strategies are as follows. (a) Enterprises pay greater attention to the treatment of environmental problems, they increase their investment in environmental protection and technological transformation, they truthfully report their emissions to the government, and they attempt to reduce environmental pollution. (b) Enterprises value their reputation among the public, they care about how their production activities are perceived by the public, they accept the public's suggestions with an open mind, and they seek to reduce environmental pollution by improving their environmental protection measures. The strategies that aim to violate the regulations include the following. (a) Enterprises aim to maximize their profits, so they choose to ignore environmental pollution problems, and they reduce their investment in environmental protection and technological transformation as much as possible. These corresponding behaviors include "underreporting," "concealing," and "illegal discharge." (b) Enterprises do not care if they incur a series of loses caused by environmental pollution arising from their production processes, and they do not care if they are penalized by the government.

(2) In this stage of the evolutionary game theory, the preference of the government can be described as follows. As a rational economic man, the government will seek to constantly optimize and maximize its interests. The cost of governance when the government performs environmental management is $C_{1}$, which mainly contains the cost of human, material, and financial resources invested in governance; the political cost of the government in managing environmental problems is $C_{2}$, and the development concept of the government is mostly influenced by the increasing trend in GDP and fiscal levies as well as by "the promotion of officials," "employment," and "maintaining stability." In the case of negative governance, the governance of environmental problems is highly consistent with the government's decision making under the preference for economic benefits, especially when considering the level of economic growth that most enterprises can bring about, wherein the degree of government's implementation efforts to address the environmental issues is $\alpha$. Furthermore, the government is limited by monitoring technology, the technological level, methods of supervision, and other aspects [63, 64], where the economic loss incurred by the government due to the loss of environmental quality is denoted by $L_{1}$. The second is that the government adheres to the concept of achieving its national strategic objectives; that is, it wishes to achieve its economic and social values and ideological aspirations and maintain a dominant position in environmental governance. As such, it is obliged to pursue public interests for the entire society or for the whole public group, and the government also guides the behaviors and processes associated with public participation [65]. The government always plays the role of protecting the safety of public property, maintaining social stability, and guiding the public's participation behavior and the process by regulating the protesters' internal psychological mechanisms and risk perception effects. Therefore, from this perspective, the government's preference tends to involve more active management strategies in the decision-making process. The potential gains to the government from improved environmental quality, mainly at the economic and ecological governance level, are denoted by $E_{1}$.

Therefore, the government will select two behavior strategies in this process of evolutionary game theory, namely, positive governance and negative governance. On the one hand, positive governance can be divided into four parts. (a) The government will pay greater attention to environmental pollution, the political cost, and the public interest when making decisions. For example, in the siting of enterprises with significant environmental pollution risks, the government can weaken the perceived risk through open procedures, information transparency, risk communication, and public participation. (b) The government will invest in special transfer payment funds to subsidize the cost of the investment associated with environmental protection and technological transformation that is incurred by polluting enterprises. (c) The government will 
increase environmental taxes and political penalties when enterprises cause pollution. Therefore, enterprises must choose to comply with the regulations, and their production activities will be subject to greater scrutiny in the form of government supervision, which will reduce environmental pollution. (d) The government can implement a series of incentivized measures to encourage the public to positively participate in environmental governance. Such measures aim to bolster the public's enthusiasm to participate in environmental governance. On the other hand, negative governance strategies can be divided into three parts. (a) The government pursues unilateral economic growth and ignores environmental pollution. (b) The government does not respond positively to public participation, which will increase the public's risk perception, exacerbate the government's crisis of confidence, and consume a higher level of political costs. (c) The government adopts a policy that entails the deregulation of enterprises, and there are no political penalties for carrying out unlawful operations by enterprises.

(3) As an important player in evolutionary game theory, the public also behaves according to the hypothesis of the rational economic man. The public is composed of a collection of different and independent individuals. In this context, "different" and "independent" lead to different demands among interest groups, as well as to different definitions and acceptance levels about environmental pollution [66]. However, all of the interest groups express the same requirements for a good environment. In addition, the public has the same economic needs. The increase in employment opportunities brought about by the development of enterprises and the growth in the social economy will benefit the public, and this places higher and stricter demands on government and corporate environmental governance. The public will have different strategic options in the evolutionary game. The response of the public is based on their perception of risk. Based on the above, the public will pay greater attention to economic interests, employment, and other factors, and less attention will be paid to environmental concerns. This is because the level of environmental pollution is not obvious in the early stage of the evolutionary game [67]. Therefore, the public readily engages in passive participation. $L_{3}$ indicates the loss of environmental quality to the public, including health, the living environment, and asset values. In the later stage, the degree of environmental pollution is very serious, and this results in greater demands among the public for a better living environment. Therefore, the public will show a preference for addressing issues related to environmental quality, and they will choose active participation. At this time, the government also hopes to maintain its legitimate rights and interests through the channels such as communication, consultation, and negotiation [68]. The government's reward for public participation in the governance of environmental issues is denoted by $A$, which minimizes the risk loss caused by neighborhood avoidance projects, and its behavior will also have an impact on political costs. The participation cost of public participation in the governance of environmental issues is denoted by $C_{4}$, including the participation and monitoring behavior under the information cost, opportunity cost, and even infringement cost. $E_{3}$ denotes the gain brought to the public by the improvement of environmental quality, including health and the living environment. $E_{4}$ is the psychological gain reaped by the public when they participate in the governance of environmental issues.

The public's active participation can be divided into three parts. (a) The public shows a greater concern for environmental issues and is more aware of the environmental quality and risks to the environment. At the same time, there is a greater demand for environmental quality. (b) The public actively responds to the government's regulatory policies and is willing to communicate its demands to the government when participating in the governmental decision-making process regarding environmental issues. (c) The public reinforces the supervision of enterprises and actively evaluates their behavior. In the case of passive participation, the following can be observed. (a) The public shows a low level of concern for environmental quality. The public is more concerned about the employment and income opportunities that are offered by enterprises and makes fewer demands about environmental quality. Therefore, the public does not pay enough attention to the environmental pollution caused by enterprises. (b) The public is not interested in governmental measures that aim to address environmental problems. (c) The public may not participate in supervision because of the costs and technology that would be required to carry out such supervision, and it may also decline to participate out of fear. The variables are shown in Table 1.

The core concept of the evolutionary game is the evolutionary stable strategy, which seeks to study how the participants of the game choose and adjust their strategies autonomously among possible behavior patterns according to different kinds of laws, so as to evolve toward the goal of an evolutionary stable strategy in complex and random interactions, leading to the emergence of the macroscopic equilibrium state of evolutionary stable strategy. When in the evolutionary stable strategy, even if some individuals in the whole group change their strategies, this strategy change will interfere with the stability of the whole evolutionary game system for a short period; however, due to the existence of a specific strategy with higher fitness (gain) than the average fitness (gain), after a period of dynamic adjustment, some individuals who changed their strategies will still adjust back 
TABLE 1: Variables and definitions of game theory.

\begin{tabular}{|c|c|c|c|}
\hline Variables & Definitions & Variables & Definitions \\
\hline$C_{1}$ & The cost of environmental governance & $F_{1}$ & $\begin{array}{l}\text { The environmental tax paid by the enterprise when it is } \\
\text { compliant with the regulations }\end{array}$ \\
\hline$C_{2}$ & $\begin{array}{c}\text { The political cost of the government's environmental } \\
\text { governance }\end{array}$ & $F_{2}$ & $\begin{array}{l}\text { The environmental tax paid by the enterprise when it } \\
\text { violates the regulations }\end{array}$ \\
\hline$C_{3}$ & $\begin{array}{c}\text { The cost of the enterprises' investment in } \\
\text { environmental protection and technological } \\
\text { transformation }\end{array}$ & $L_{1}$ & $\begin{array}{l}\text { The economic loss that is incurred by the government as a } \\
\text { result of the decline in environmental quality }\end{array}$ \\
\hline$C_{4}$ & $\begin{array}{l}\text { The cost of the public's participation in environmental } \\
\text { governance }\end{array}$ & $L_{2}$ & $\begin{array}{l}\text { The economic loss incurred by } t \\
\text { the decline in enviro }\end{array}$ \\
\hline$R_{1}$ & $\begin{array}{l}\text { The main business income of enterprises when they are } \\
\text { compliant with the regulations }\end{array}$ & $L_{3}$ & $\begin{array}{l}\text { The loss incurred by the public as a result of the decline in } \\
\text { environmental quality }\end{array}$ \\
\hline$R_{2}$ & $\begin{array}{l}\text { The main business income of enterprises when they } \\
\text { violate the regulations }\end{array}$ & $E_{1}$ & $\begin{array}{l}\text { The benefits accrued to the government as a result of the } \\
\text { improvement in environmental quality }\end{array}$ \\
\hline$\alpha$ & $\begin{array}{l}\text { The degree of implementation of environmental } \\
\text { governance by the government }\end{array}$ & $E_{2}$ & $\begin{array}{c}\text { The improvement in the enterprises' reputation as a result } \\
\text { of their efforts to improve environmental quality }\end{array}$ \\
\hline$\beta$ & $\begin{array}{l}\text { The degree of public's participation in environmental } \\
\text { governance }\end{array}$ & $E_{3}$ & $\begin{array}{l}\text { The benefits accrued to the public with respect to the } \\
\text { improvement in environmental quality }\end{array}$ \\
\hline$\theta$ & $\begin{array}{c}\text { The ratio of the government's tax payment to the } \\
\text { income of enterprises }\end{array}$ & $E_{4}$ & $\begin{array}{l}\text { The psychological benefits that result from public } \\
\text { participation in environmental problem governance }\end{array}$ \\
\hline$P$ & $\begin{array}{l}\text { The political penalties incurred by enterprises when } \\
\text { they violate the regulations }\end{array}$ & $A$ & $\begin{array}{c}\text { The government's reward for encouraging public } \\
\text { participation in the governance of environmental } \\
\text { problems }\end{array}$ \\
\hline$T$ & & & carry out the enterprises' environmental governance \\
\hline
\end{tabular}

to their original strategies, and eventually, the game system is again in the state of an evolutionary stable strategy.

In this paper, it is assumed that the probability that enterprises will actively abide by the regulations and follow the government's strategy for environmental governance is $x$ $(0 \leq x \leq 1)$. Therefore, the probability that enterprises will violate the regulations and refuse to follow the government's strategy for environmental governance is $1-x$. At the same time, the probability that the government will actively govern environmental problems is $y(0 \leq y \leq 1)$, and the probability that the government will negatively govern environmental problems is $1-y$. In addition, the probability that the public will choose to positively participate in environmental governance is $z(0 \leq z \leq 1)$, so the probability that the public will choose to negatively participate in environmental governance is $1-z$.

In the environmental governance system, there are eight strategies for government-enterprise-public (due to space limitations herein, this paper takes the first strategy $I_{1}(0,0,0)$ as an example). $I_{1}$ : when enterprises violate the regulations, the government has negative governance, and the public has negative participation $(x=0, y=0$, and $z=0)$. The payment matrix is

$$
\begin{aligned}
R_{2} & -\alpha F_{2}+\alpha T-\beta L_{2}-\alpha P \\
& -\alpha C_{2}+\theta R_{2}-L_{1}+\alpha F_{2}+\alpha P \\
& -\beta C_{4}+\beta E_{4}-L_{3} .
\end{aligned}
$$

The income of the enterprise can be calculated by the elements as follows. The enterprise's revenue is the main business income at the time of violation $R_{2}$. The special fund allocated to the enterprise to deal with environmental issues from the government, which is related to the strength of government's governance, is $\alpha T$.

The expenditure of enterprises can be calculated by the elements as follows. The political penalty imposed by the government, which is related to the strength of government's governance, such as the proportion of negative governance, is $\alpha P$. And the economic loss caused by the loss of environmental quality to the enterprise because of environmental protection negative publicity, the public buys less of its products. It is also related to public participation and attention $\beta L_{2}$. The environmental tax payment that is incurred in the event of a violation, which is related to the strength of government's governance, is denoted by $\alpha F_{2}$.

The income of the government can be calculated by the elements as follows. The government's revenue is the enterprise's violation of the proportional main business income. It can be understood as a GDP indicator, and part of it is the tax in reality, which is denoted by $\theta R_{1}$. The political penalty imposed by the government, which is related to the strength of government's governance, such as the proportion of negative governance, is denoted by $\alpha P$. The environmental tax payment that is due in the event of a violation, which is related to the strength of government's governance, is denoted by $\alpha F_{2}$.

The expenditure of the government can be calculated by the elements as follows. The government's expenditure is the economic loss that is incurred by the government as a result of the loss of environmental quality, which is denoted by $L_{1}$. The negative cost from political externalities, which is also related to the strength of government governance, is denoted by $\alpha C_{2}$.

The income of the public can be calculated by the elements as follows. The gain of the public, including the gain 
arising from improved environmental quality, is related to the participation strength and is denoted by $\beta E_{4}$.

The expenditure of the public can be calculated by the elements as follows. The expenditure of the public, which is related to its participation strength, is the cost of participation in environmental problems and is denoted by $\beta C_{4}$. The loss incurred by the public as a result of the decline in environmental quality is expressed as $L_{3}$.
By analogy, the payment matrices of other strategies are shown in Table 2.

When the government carries out environmental governance, the expected benefits and population utility of the enterprises "compliance emissions" and "violation emissions" are shown below:

$$
\begin{aligned}
U_{x 1}= & y z\left(-C_{3}+R_{1}+T-F_{1}+E_{2}\right)+y(1-z)\left(-C_{3}+R_{1}+T-F_{1}+\beta E_{2}\right) \\
& +(1-y) z\left(-C_{3}+R_{1}+\alpha T-\alpha F_{1}+E_{2}\right)+(1-y)(1-z)\left(-C_{3}+R_{1}+\alpha T-\alpha F_{1}+\beta E_{2}\right), \\
U_{x 2}= & y z\left(R_{2}-F_{2}-L_{2}-P\right)+y(1-z)\left(R_{2}-F_{2}-\beta L_{2}-P\right) \\
& +(1-y) z\left(R_{2}-\alpha F_{2}+\alpha T-L_{2}-\alpha P\right)+(1-y)(1-z)\left(R_{2}-\alpha F_{2}+\alpha T-\beta L_{2}-\alpha P\right) \\
\bar{U}_{x}= & x U_{x 1}+(1-x) U_{x 2} .
\end{aligned}
$$

The expected benefits and population utility of the government's choice to engage in positive and negative governance are shown below:

$$
\begin{aligned}
U_{y 1}= & x z\left(-C_{1}+C_{2}+\theta R_{1}+E_{1}-T+F_{1}-A\right)+x(1-z)\left(-C_{1}+C_{2}+\theta R_{1}+E_{1}-T+F\right)_{1} \\
& +(1-x) z\left(-C_{1}+C_{2}+\theta R_{2}-L_{1}+F_{2}+P-A\right)+(1-x)(1-z)\left(-C_{1}+C_{2}+\theta R_{2}-L_{1}+F_{2}+P\right), \\
U_{y 2}= & x z\left(-\alpha C_{2}+\theta R_{1}+E_{1}-\alpha T+\alpha F_{1}\right)+x(1-z)\left(-\alpha C_{2}+\theta R_{1}+E_{1}-\alpha T+\alpha F_{1}\right) \\
& +(1-x) z\left(-\alpha C_{2}+\theta R_{2}-L_{1}+\alpha F_{2}+\alpha P\right)+(1-x)(1-z)\left(-\alpha C_{2}+\theta R_{2}-L_{1}+\alpha F_{2}+\alpha P\right) \\
\bar{U}_{y}= & y U_{y 1}+(1-y) U_{y 2} .
\end{aligned}
$$

The expected benefits and population utility of the public's active and passive participation are shown below:

$$
\begin{aligned}
U_{z 1}= & x y\left(-C_{4}+E_{3}+E_{4}+A\right)+x(1-y)\left(-C_{4}+E_{3}+E_{4}\right) \\
& +(1-x) y\left(-C_{4}+E_{4}-L_{3}+A\right)+(1-x)(1-y)\left(-C_{4}+E_{4}-L_{3}\right), \\
U_{z 2}= & x y\left(-\beta C_{4}+\beta E_{4}+E_{3}\right)+x(1-y)\left(-\beta C_{4}+\beta E_{4}+E_{3}\right) \\
& +(1-x) y\left(-\beta C_{4}+\beta E_{4}-L_{3}\right)+(1-x)(1-y)\left(-\beta C_{4}+\beta E_{4}-L_{3}\right) \\
\bar{U}_{z}= & z U_{z 1}+(1-z) U_{z 2} .
\end{aligned}
$$

Therefore, since the various interested entities, such as the government, enterprises, and the public, are making decisions under the condition of incomplete information and since the change in participants' strategies will be accompanied by additional costs, the various parties can only adopt limited rational strategic actions to compete with other participants. According to the Malthusian view, an evolutionary game analysis to examine the information asymmetry problem in mass events of environmental issues is possible by using a replication dynamic equation. The replicative dynamics refer to an analysis of the path of finite rational individuals who can adjust their strategies and achieve an equilibrium state. The core idea is that the proportion of different strategies adopted in a group will vary with the difference between the expected return and the average return of the group of different strategies. Strategies with higher than group average returns are considered as being able to adapt to the evolutionary process of the group, and they are more resistant to the invasion of mutation strategies, so they will be adopted more often; conversely, strategies with lower than group average returns will be adopted less often. In the end, the strategy that is higher than 
TABle 2: Payment matrix of the game theory among enterprises, the government, and the public.

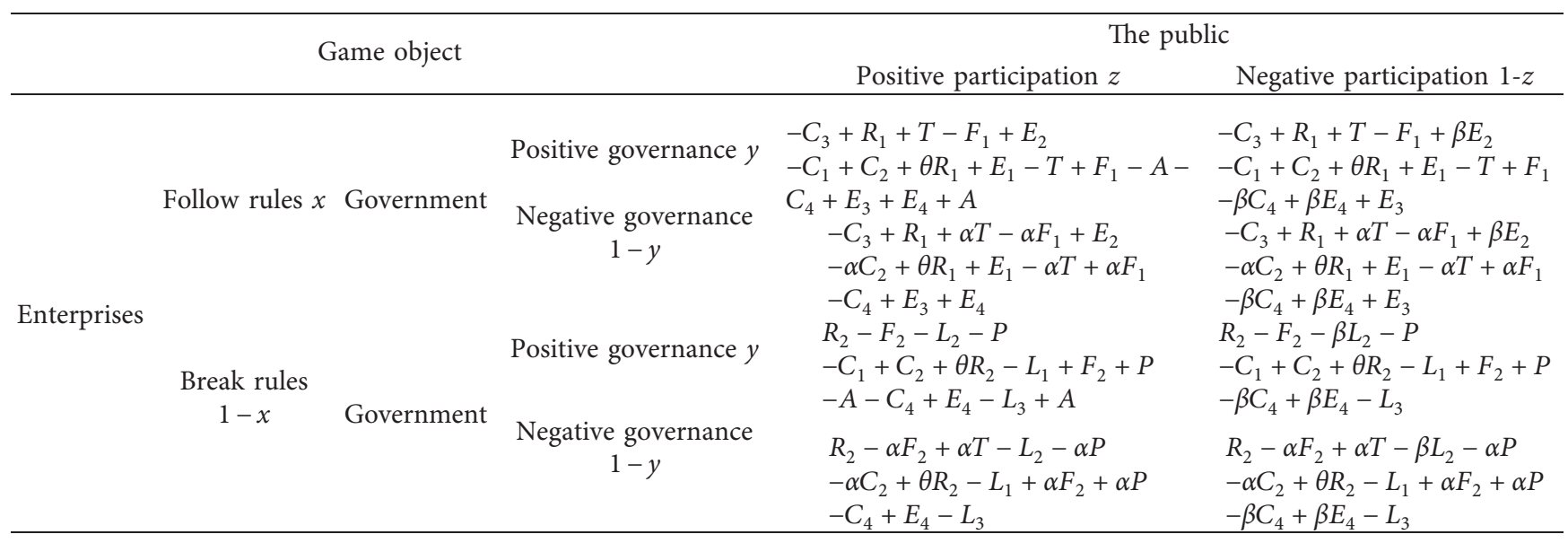

the average group return is selected and the strategy that is lower than the average group return is gradually eliminated. According to the replication dynamic equation, $d x / d t$, which expresses the growth rate of local enterprises' compliance with regulations and governance strategies, is directly proportionate to the difference between the expected revenue and the average expected revenue in the case of local enterprises' compliance with regulations and governance strategies, as shown by the following formula:

$$
\begin{aligned}
\frac{\mathrm{d} x}{\mathrm{~d} t} & =x\left(U_{x 1}-\bar{U}_{x}\right) \\
& =x(1-x)[a+b(y-1)+c(z-1)] .
\end{aligned}
$$

Similarly, the replication dynamic equation of the game between the government and the public can be formulated. The following three-dimensional dynamical system $(K)$ can then be deduced from the replication dynamic equations of the three populations:

$$
\left\{\begin{array}{l}
F(x)=\frac{\mathrm{d} x}{\mathrm{~d} t}=x\left(U_{x 1}-\bar{U}_{x}\right)=x(1-x)[a+b(y-1)+c(z-1)] \\
F(y)=\frac{\mathrm{d} y}{\mathrm{~d} t}=y\left(U_{y 1}-\bar{U}_{y}\right)=y(1-y)(d+e x-f z), \\
F(z)=\frac{\mathrm{d} z}{\mathrm{~d} t}=z\left(U_{z 1}-\bar{U}_{z}\right)=z(1-z)(g+f y) .
\end{array}\right.
$$

To simplify the operation, the intermediate variables from the above equation are defined as follows:

$$
\begin{aligned}
& a=-C_{3}+R_{1}-R_{2}-F_{1}+F_{2}+T+P+E_{2}+L_{2}, \\
& b=(1-\alpha)\left(F_{2}-F_{1}+P\right)+T, \\
& c=(1-\beta)\left(E_{2}+L_{2}\right) \\
& d=-C_{1}+(1+\alpha) C_{2}+(1-\alpha)\left(F_{2}+P\right), \\
& e=(1-\alpha)\left(F_{1}-F_{2}-T-P\right), \\
& f=A \\
& g=(1-\beta)\left(E_{4}-C_{4}\right) .
\end{aligned}
$$

4.2. Equilibrium Analysis. Based on the equilibrium analysis of the above evolutionary process, we can obtain the equilibrium points in the following four cases:

(1) The eight triple populations adopted pure-strategy equilibrium points, which include $(0,0,0),(0,0,1)$, $(0,1,0),(0,1,1),(1,0,0),(1,0,1),(1,1,0),(1,1,1)$. In terms of a system $(K)$, when the value of $x$ is 0 or 1 , the value of $y$ is 0 or 1 , and the value of $z$ is 0 or 1 , and the following equalities hold infinitely: $\mathrm{d} x / \mathrm{d} t=0$, $\mathrm{d} y / \mathrm{d} t=0, \mathrm{~d} z / \mathrm{d} t=0$. Therefore, the pure-strategy points that were adopted for the above eight groups are all equilibrium points. 
(2) There were no double populations that adopted pure-strategy equilibrium points:

$$
\left.\begin{array}{l}
A: x=0, \quad y=0, z \neq 0 / 1, F(x)=0, F(y)=0, F(z) \\
B: x=0, \quad y=1, z \neq 0 / 1, F(x)=0, F(y)=0, F(z) \\
C: x=1, \quad y=0, z \neq 0 / 1, F(x)=0, F(y)=0, F(z) \\
D: x=1, \quad y=1, z \neq 0 / 1, F(x)=0, F(y)=0, F(z) \\
E: x=0, \quad z=0, y \neq 0 / 1, F(x)=0, F(z)=0, F(y) \\
F: x=0, \quad z=1, y \neq 0 / 1, F(x)=0, F(z)=0, F(y) \\
\text { G: } x=1, \quad z=0, y \neq 0 / 1, F(x)=0, F(z)=0, F(y) \\
H: x=1, \quad z=1, y \neq 0 / 1, F(x)=0, F(z)=0, F(y) \\
I: y=0, \quad z=0, x \neq 0 / 1, F(y)=0, F(z)=0, F(x) \\
J: y=0, \quad z=1, x \neq 0 / 1, F(y)=0, F(z)=0, F(x) \\
K: y=1, \quad z=0, x \neq 0 / 1, F(y)=0, F(z)=0, F(x) \\
L: y=1, \quad z=1, x \neq 0 / 1, F(y)=0, F(z)=0, F(x)
\end{array}\right\} \Longrightarrow \text { equation without solution. }
$$

(3) Four single populations adopted pure-strategy equilibrium points as follows.

(B) When $x=1$ and $y, z \neq 0$ or 1 ,

(A) When $x=0$ and $y, z \neq 0$ or 1 ,

$$
A\left\{\begin{array}{l}
F(x)=0 \\
F(y)=y(1-y)(d-f z)=0 \\
F(z)=z(1-z)(g+f y)=0 .
\end{array}\right.
$$

$$
B\left\{\begin{array}{l}
F(x)=0 \\
F(y)=y(1-y)(d+e-f z)=0 \Longrightarrow\left(1,-\frac{g}{f}, \frac{d+e}{f}\right) . \\
F(z)=z(1-z)(g+f y)=0
\end{array}\right.
$$

(C) When $y=0$ and $x, z \neq 0$ or 1 ,

$$
C\left\{\begin{array}{l}
F(x)=x(1-x)[a-b+c(z-1)]=0 \\
F(y)=0 \\
F(z)=z(1-z) g=0
\end{array} \Longrightarrow\right. \text { equation without solution. }
$$

(D) When $y=1$ and $x, z \neq 0$ or 1 ,

$$
D\left\{\begin{array}{l}
F(x)=x(1-x)[a+c(z-1)]=0 \\
F(y)=0 \\
F(z)=z(1-z)(g+f)=0 .
\end{array} \Longrightarrow\right. \text { equation without solution. }
$$


(E) When $z=0$ and $x, y \neq 0$ or 1 ,

$$
E\left\{\begin{array}{l}
F(x)=x(1-x)[a+b(y-1)-c]=0 \\
F(y)=y(1-y)(d+e x)=0 \\
F(z)=0
\end{array} \Longrightarrow\left(-\frac{d}{e}, 1+\frac{-a+c}{b}, 0\right)\right.
$$

(F) When $z=1$ and $x, y \neq 0$ or 1 ,

(4) There was one hybrid strategy balanced point, which can be described as follows:
When $x, y, z \neq 0$ or 1 , system $(K)$ satisfies the following equation:

$$
\left\{\begin{array} { l } 
{ F ( x ) = x ( 1 - x ) ( a + b y - b + c z - z ) = 0 } \\
{ F ( y ) = y ( 1 - y ) ( d + e x - f z ) = 0 } \\
{ F ( z ) = z ( 1 - z ) ( g + f y ) = 0 }
\end{array} \Longrightarrow \left\{\begin{array}{l}
a+b y-b+c z-z=0, \\
d+e x-f z=0, \\
g+f y=0 .
\end{array}\right.\right.
$$

From the above three-dimensional first-order equations, we can draw the following conclusions:

$$
\begin{aligned}
& x^{*}=\frac{b f-c d-a f+b g+c f}{c e}, \\
& y^{*}=-\frac{g}{f}, \\
& z^{*}=\frac{b f-a f+b g+c f}{c f} .
\end{aligned}
$$

In the evolutionary game theory of multiple populations, the necessary and sufficient condition of the evolutionarily stable equilibrium point $\boldsymbol{I}$ is that $\boldsymbol{I}$ should have a strict Nash equilibrium, in accordance with game theory. If $I$ enters into a gradual stable state, it must be in a strict Nash equilibrium, that is, a pure-strategy equilibrium. The stability of equilibrium points is analyzed based on the above eight pure- strategy equilibrium solutions. According to Lyapunov's stability theory, when all eigenvalues $\lambda$ are less than zero in the Jacobian matrix, the equilibrium point must be asymptotically stable. When all eigenvalues $\lambda$ are greater than zero in the Jacobian matrix, the equilibrium point must be unstable. The equilibrium point must be unstable when there is one eigenvalue $\lambda$ less than zero and two eigenvalues greater than zero or one eigenvalue greater than zero and two eigenvalues less than zero. Based on the Lyapunov stability theory, the eigenvalues in the Jacobian matrix can assess the asymptotic stability of the equilibrium point of the system. In other words, all eigenvalues in the Jacobian matrix are negative real parts. This is a necessary and sufficient condition for replicating the equilibrium point of the dynamical system to satisfy the evolutionary stable strategy. Therefore, the Jacobian matrix of system $(K)$ can be expressed by the following formula:

$$
\left[\begin{array}{ccc}
(1-2 x)[a+b(y-1)+c(z-1)] & b x(1-x) & c x(1-x) \\
e y(1-y) & (1-2 y)(d+e x-f z) & -f y(1-y) \\
0 & f z(1-z) & (1-2 z)(g+f y)
\end{array}\right]
$$

According to formula (17), the eight pure-strategy equilibrium points and their eigenvalues of system $(K)$ are shown in Table 3.

By referring to Table 3, the judgment methods that were used to determine the stability of each equilibrium point will be discussed by taking $I_{1}(0,0,0)$ as an example. The Jacobian matrix of system $(K)$ at equilibrium point $I_{1}(0,0,0)$ is as follows:

$$
J_{1}=\left|\begin{array}{ccc}
a-b-c & 0 & 0 \\
0 & d & 0 \\
0 & 0 & g
\end{array}\right|
$$

Under the above conditions, the eigenvalues of the Jacobian matrix are as follows: $\lambda_{1}=a-b-c, \quad \lambda_{2}=d, \lambda_{3}=g$. When $a-b-c<0, d<0$ and $g<0$, all eigenvalues are less than zero, so $I_{1}(0,0,0)$ is asymptotically stable, and this is termed the 
TABLE 3: Equilibrium points and eigenvalues of system $(K)$.

\begin{tabular}{|c|c|c|c|c|}
\hline Equilibrium point & & acobian matrix & Eigenvalues & Asymptotic stability condition \\
\hline$I_{1}(0,0,0)$ & $J_{1}=$ & $=\left|\begin{array}{ccc}a-b-c & 0 & 0 \\
0 & d & 0 \\
0 & 0 & g\end{array}\right|$ & $\begin{array}{l}\lambda_{1}=a-b-c \\
\lambda_{2}=d \\
\lambda_{3}=g\end{array}$ & $\begin{array}{l}\lambda_{1}<0 \\
\lambda_{2}<0 \\
\lambda_{3}<0 \\
\end{array}$ \\
\hline$I_{2}(0,0,1)$ & $J_{2}=$ & $\left|\begin{array}{ccc}a-b & 0 & 0 \\
0 & d-f & 0 \\
0 & 0 & -g\end{array}\right|$ & $\begin{array}{l}\lambda_{1}=a-b \\
\lambda_{2}=d-f \\
\lambda_{3}=-g\end{array}$ & $\begin{array}{l}\lambda_{1}<0 \\
\lambda_{2}<0 \\
\lambda_{3}<0\end{array}$ \\
\hline$I_{3}(0,1,0)$ & $J_{3}=$ & $\left|\begin{array}{ccc}a-c & 0 & 0 \\
0 & -d & 0 \\
0 & 0 & f+g\end{array}\right|$ & $\begin{array}{l}\lambda_{1}=a-c \\
\lambda_{2}=-d \\
\lambda_{3}=f+g\end{array}$ & $\begin{array}{l}\lambda_{1}<0 \\
\lambda_{2}<0 \\
\lambda_{3}<0\end{array}$ \\
\hline$I_{4}(0,1,1)$ & $J_{4}=$ & $\left|\begin{array}{ccc}a & 0 & 0 \\
0 & f-d & 0 \\
0 & 0 & -f-g\end{array}\right|$ & $\begin{array}{l}\lambda_{1}=a \\
\lambda_{2}=f-d \\
\lambda_{3}=-f-g\end{array}$ & $\begin{array}{l}\lambda_{1}<0 \\
\lambda_{2}<0 \\
\lambda_{3}<0\end{array}$ \\
\hline$I_{5}(1,0,0)$ & $J_{5}=\mid$ & $\begin{array}{ccc}-a+b+c & 0 & 0 \\
0 & d+e & 0 \\
0 & 0 & g\end{array} \mid$ & $\begin{array}{l}\lambda_{1}=-a+b+c \\
\lambda_{2}=d+e \\
\lambda_{3}=g\end{array}$ & $\begin{array}{l}\lambda_{1}<0 \\
\lambda_{2}<0 \\
\lambda_{3}<0\end{array}$ \\
\hline$I_{6}(1,0,1)$ & $J_{6}=\left.\right|^{-c}$ & $\begin{array}{ccc}a+b & 0 & 0 \\
0 & d+e-f & 0 \\
0 & 0 & -g\end{array} \mid$ & $\begin{array}{l}\lambda_{1}=-a+b \\
\lambda_{2}=d+e-f \\
\lambda_{3}=-g\end{array}$ & $\begin{array}{l}\lambda_{1}<0 \\
\lambda_{2}<0 \\
\lambda_{3}<0\end{array}$ \\
\hline$I_{7}(1,1,0)$ & $J_{7}=\left.\right|^{-}$ & $\begin{array}{ccc}a+c & 0 & 0 \\
0 & -d-e & 0 \\
0 & 0 & f+g\end{array}$ & $\begin{array}{l}\lambda_{1}=-a+c \\
\lambda_{2}=-d-e \\
\lambda_{3}=f+g\end{array}$ & $\begin{array}{l}\lambda_{1}<0 \\
\lambda_{2}<0 \\
\lambda_{3}<0\end{array}$ \\
\hline$I_{8}(1,1,1)$ & $J_{8}=\mid \begin{array}{c}-a \\
0 \\
0\end{array}$ & $\begin{array}{cc}0 & 0 \\
-d-e+f & 0 \\
0 & -f-g\end{array}$ & $\begin{array}{l}\lambda_{1}=-a \\
\lambda_{2}=-d-e+f \\
\lambda_{3}=-f-g\end{array}$ & $\begin{array}{l}\lambda_{1}<0 \\
\lambda_{2}<0 \\
\lambda_{3}<0\end{array}$ \\
\hline
\end{tabular}

convergence point. When $a-b-c>0, d>0, g>0$, all eigenvalues are greater than zero, so $I_{1}(0,0,0)$ is unstable, and this is known as source. When there is one eigenvalue less than zero and two greater than zero or one greater than zero and two less than zero, $I_{1}(0,0,0)$ is unstable and it becomes a saddle point. Similarly, the asymptotic stability of $I_{2}, I_{3}, I_{4}, I_{5}, I_{6}, I_{7}, I_{8}$ can be obtained. From the above analysis, it can be concluded that, in this stage, the unstable points are fuzzy in respect to the game involving the government, enterprises, and the public, and this reflects the actual situation. Therefore, the following simulation analysis was carried out for each equilibrium point.

\section{Construction of the Small-Signal Model and Measurement Simulation}

In this paper, under the anti-interference mode (discrete events), a small-signal calculation was carried out for the subsystems of a complex environment system; that is, in the MATLAB program, a set of parameters was selected for each equilibrium point to monitor and analyze the stability of political costs in the complex environment system (i.e., whether the equilibrium point is the expected ideal equilibrium point), and then the value range and participation factor of the parameters were quickly obtained. At the same time, by debugging these parameters, all elements of the complex environmental governance system can reach a stable and ideal equilibrium state, and the optimal regulation strategy of the political cost of environmental problems is put forward. Based on the above equilibrium analysis, we can only make a qualitative judgment about the asymptotic stability of the equilibrium point. It is not possible to accurately describe the interaction and its influence on system stability in terms of each variable at each equilibrium point in system $(K)$. Therefore, the small-signal model can be used to further analyze the stability of the above eight equilibrium points, which is particularly useful for the measurement and analysis of the political cost in the evolutionary game theory.

5.1. Construction of the Small-Signal Model. The behavioral characteristics or behavioral trajectory of a dynamical system can be described by a group of $n$-dimensional first-order ordinary differential nonlinear equations, where $n$ represents the order of the system and the number of state variables. At the same time, the state of the system can be represented by any $n$-dimensional linear and independent variables of the system state. Finally, the minimum set of dynamical variables of the system is determined. In addition, this process can provide a complete description of the system's behavior as well as the input variables of the system. The small-signal model of a dynamical system is constructed by linearizing and recombining all of the nonlinear state-space equations that are contained within it $[69,70]$. The specific expression is as follows:

$$
\left\{\begin{array}{l}
\frac{\mathrm{d} \Delta X}{\mathrm{~d} t}=A \Delta X=B \Delta U, \\
\Delta Y=C \Delta X+D \Delta U,
\end{array}\right.
$$

where $\Delta \boldsymbol{X}$ is the $n$-dimensional state variable; $\Delta \boldsymbol{Y}$ is the $m$ dimensional output variable; $\Delta U$ is the $r$-dimensional input variable; $\boldsymbol{A}$ is the matrix order $n$ by $n ; \boldsymbol{B}$ is the matrix order $n$ by $r$; $C$ is the matrix order $m$ by $n$; and $\boldsymbol{D}$ is the matrix order $m$ by $r$. 
By referring to formula (6) of the three-dimensional system, it can be seen that system $(K)$ is a dynamical system with relatively simple dynamical properties. The appropriate state variables can be analyzed and selected from the system. According to the process of constructing a small-signal model, as described above, the nonlinear state-space equations can be linearized one by one. The corresponding small-signal model can then be obtained. Furthermore, the three-dimensional state variables and the matrix $\boldsymbol{A}$ of order $3 \times 3$ can be drawn up in the small-signal model. The state variable $\boldsymbol{\Delta X}$ is $[x, y, z]^{\mathrm{T}}$, and the state matrix $\boldsymbol{A}$ determines the Jacobian matrix, as follows:

$$
\left[\begin{array}{c}
(1-2 x)[a+b(y-1)+c(z-1)] \\
e y(1-y) \\
0
\end{array}\right.
$$

5.2. Stability Analysis. From the perspective of principalagent theory, political costs are not only an economic and quantitative concept but also contain specific political and social content. In the absence of reasonable constraints and supervision, local governments may deviate, to a certain extent, from the public's agentic goals in relation to environmental governance, which in turn generates public resistance and consumes political costs. This process is characterized by many ambiguities and the dynamic game of signaling under incomplete information [71], and it belongs to a complex public crisis system. In this system, the government, within the context of environmental governance, must consider the relationship between political costs and political benefits; that is, it seeks to use the least political resources for environmental issues to obtain maximum political benefits. Therefore, in the process of environmental governance, there is an evolutionary game behavior among the government, enterprises, and the public, and the three parties are also continuously learning and imitating to find the better strategy through a limited trial and error process, whereby they can adjust and improve and eventually develop a stable strategy. This game behavior will affect the local government's policy orientation, the government's enforcement and supervision of environmental protection, the citizens' satisfaction with the government, and so on, which will have an impact on the political costs of environmental issues and thus affect the stability of the whole game system. The stability of political costs needs to be further determined by the test method of the evolutionary game. Therefore, by analyzing the evolutionary game behavior between government-enterprise-public participants, establishing the conditions for each party's behavior to converge to a stable state, and using a small-signal model to establish a reasonable political cost control mechanism to increase the effectiveness of policies, the government can achieve public reproduction of environmental governance and reduce negative externalities.

In the process of system control, the actual information must be fed back to the control body in time, and then the control body adjusts its control function through various organizations according to the feedback information and finally ensures the realization of the control object [72]. Complex system theory uses fuzzy system identification and functional simulation as research methods, and system operating state, function, and behavior are taken as analysis objects, so that the goal of controlling and balancing dynamic systems under complex environmental conditions is achieved stably, requiring the control subject to have a powerful regulatory function [73]. The role of political costs means that in the current government governance situation, the government should effectively allocate and use political resources to achieve stability and the optimal configuration of the environmental governance system, so as to ultimately obtain the greatest political impact benefits with the smallest political cost input [74]. Therefore, the government needs to pay attention to reasonableness in terms of political costs in order to ensure the stability of the governance system. When the system evolution game is at a nonideal equilibrium point, the small-signal model can analyze the adjustment of the parameters in the system, and it is possible to reach the ideal equilibrium point in the end. Through the measurement and analysis of the small-signal model, the optimal and fastest adjustment parameters can be effectively obtained under anti-interference conditions.

In this paper, we aim to produce a more intuitive analysis of the relationship between the economic cost and the political cost at each balanced point in environmental governance. MATLAB was employed to write the corresponding program that was based on the small-signal model described above. At the same time, a set of parameters was selected for each equilibrium point to ensure the asymptotic stability of the system. Moreover, this paper discusses the root locus and participation factors of equilibrium points when selecting different parameters by carrying out a simulation analysis. Finally, the influence of the political cost on the stability of the system can be judged, and the leading governance entities at different equilibrium points can be determined. Considering restrictions with respect to the scope of this paper, three representative points were selected for analysis. The analyses of the remaining five points are detailed in Appendixes A-C.

5.2.1. Stability of $I_{1}$. According to the initial values described in Table 4, the calculation shows that $I_{1}$ satisfies $a-b-c$ $<0, \quad d<0, g<0$. Furthermore, according to the game equilibrium analysis, equilibrium point $I_{1}$ is asymptotically stable at this time. Similarly, we set the initial values of the equilibrium points $I_{2}, I_{5}$, and $I_{6}$, which are shown in Tables 5-7 of Appendix A. In order to verify the accuracy of the small-signal model, the initial values of $x, y$, and $z$ were 
TABLE 4: Parameter values of all variables at balanced point $I_{1}$.

\begin{tabular}{lccccccc}
\hline Variable & Parameter value & Variable & Parameter value & Variable & Parameter value & Variable & Parameter value \\
\hline$C_{1}$ & 2 & $\alpha$ & 0.6 & $A$ & 0.3 & $L_{1}$ & 2 \\
$C_{2}$ & 0.5 & $\beta$ & 0.5 & $E_{1}$ & 1 & $L_{2}$ & 2 \\
$C_{3}$ & 2 & $\theta$ & 0.5 & $E_{2}$ & 1 & $L_{3}$ & 2 \\
$C_{4}$ & 2 & $P$ & 1 & $E_{3}$ & $F_{1}$ & 3 \\
$R_{1}$ & 5 & $T$ & 3 & $E_{4}$ & 0.5 & $F_{2}$ & 1 \\
$R_{2}$ & 10 & & & & & \\
\hline
\end{tabular}

TABLe 5: Parameter values of all variables at balanced point $I_{2}$.

\begin{tabular}{lccccccc}
\hline Variable & Parameter value & Variable & Parameter value & Variable & Parameter value & Variable & Parameter value \\
\hline$C_{1}$ & 2 & $\alpha$ & 0.6 & $A$ & 0.3 & $L_{1}$ & 2 \\
$C_{2}$ & 0.5 & $\beta$ & 0.5 & $E_{1}$ & 1 & $L_{2}$ & 2 \\
$C_{3}$ & 2 & $\theta$ & 0.5 & $E_{2}$ & 1 & $L_{3}$ & $F_{1}$ \\
$C_{4}$ & 0.5 & $P$ & 1 & $E_{3}$ & 1 & $F_{2}$ & 1 \\
$R_{1}$ & 5 & $T$ & 3 & $E_{4}$ & 2 & \\
$R_{2}$ & 10 & & & & & \\
\hline
\end{tabular}

TABLE 6: Parameter values of all variables at balanced point $I_{5}$.

\begin{tabular}{lccccccc}
\hline Variable & Parameter value & Variable & Parameter value & Variable & Parameter value & Variable & Parameter value \\
\hline$C_{1}$ & 1 & $\alpha$ & 0.6 & $A$ & 0.1 & $L_{1}$ & 2 \\
$C_{2}$ & 0.5 & $\beta$ & 0.5 & $E_{1}$ & 1 & $L_{2}$ & $L_{3}$ \\
$C_{3}$ & 2 & $\theta$ & 0.5 & $E_{2}$ & 2 & $F_{1}$ & 3 \\
$C_{4}$ & 2 & $P$ & 1 & $E_{3}$ & 1 & $F_{2}$ & 3 \\
$R_{1}$ & 10 & $T$ & 3 & $E_{4}$ & 0.5 & \\
$R_{2}$ & 10 & & & & & \\
\hline
\end{tabular}

TABLE 7: Parameter values of all variables at balanced point $I_{6}$.

\begin{tabular}{lccccccc}
\hline Variable & Parameter value & Variable & Parameter value & Variable & Parameter value & Variable & Parameter value \\
\hline$C_{1}$ & 1 & $\alpha$ & 0.5 & $A$ & 5 & $L_{1}$ & 2 \\
$C_{2}$ & 1 & $\beta$ & 0.5 & $E_{1}$ & 1 & $L_{2}$ & $L_{3}$ \\
$C_{3}$ & 2 & $\theta$ & 0.5 & $E_{2}$ & 2 & $F_{1}$ & 5 \\
$C_{4}$ & 1 & $P$ & 5 & $E_{3}$ & 1 & $F_{2}$ & 5 \\
$R_{1}$ & 10 & $T$ & 5 & $E_{4}$ & 2 & \\
$R_{2}$ & 10 & & & & & \\
\hline
\end{tabular}

selected randomly. By taking $x=0.3, y=0.6$, and $z=0.9$ as an example, this paper used MATLAB to create a dynamic evolution diagram of system $(K)$, which is shown in Figure 2. It can be seen that the final steady-state values of $x, y$, and $z$ were $[0,0,0]$ under the initial parameters. This indicates that the final stable state of system $(K)$ reaches equilibrium point $I_{1}(0,0,0)$ based on these parameters. Furthermore, this also verifies the accuracy of the small-signal model. It is worth mentioning that the initial values of $x, y$, and $z$ are random; that is, they are the results of the final dynamic evolution which will be the same if other values are assigned randomly.

Having verified the accuracy of the small-signal model described above, it was necessary to measure and analyze the political cost at balanced point $I_{1}$. Therefore, we selected the political cost of the government's environmental governance $C_{2}$ as a parameter in order to analyze the stability of the system. The process of analyzing the influence of political cost $C_{2}$ on the stability of system $(K)$ is shown in Figure 6.
By taking the initial values shown in Table 4, this paper gradually increased the value of political cost $C_{2}$ from 0 to 10 in an increased step size of 0.1 . The root locus of the system is shown in Figure 6(a). It can be seen that with the continuous increase in political cost $C_{2}$, system $(K)$ gradually moves from being stable to unstable. At the same time, the value of $C_{2}$ is 0.8 at the critical stable point. Therefore, when political cost $C_{2}$ is less than 0.8 , system $(K)$ has small-signal stability. In addition, if the value of $C_{2}$ is 0.8 and other parameters are maintained, the conclusion can be verified. This shows that after the calculation, $a-b-c<0, \quad d>0, \quad g<0$. Based on the equilibrium analysis of the game theory model, it is evident that equilibrium point $I_{1}$ at this time is a saddle point and it is unstable. Therefore, the stable region of political cost $C_{2}$ is from 0 to 0.8 . Moreover, with the increase in the value of $C_{2}$, the stability of the system will decrease. In respect to the root locus analysis, the most important information can be obtained by analyzing the trend and its influencing 


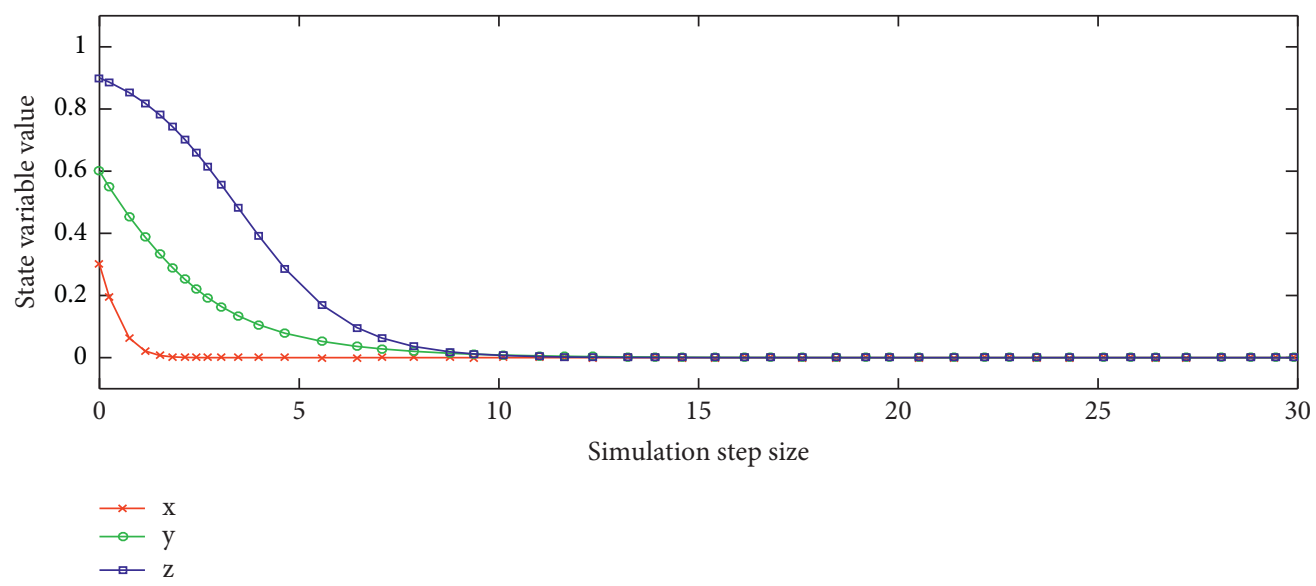

FIGURE 2: Dynamic evolution of system $(K)$ at equilibrium point $I_{1 .}$. Annotation. The value of the state variable represents the value of $\Delta \boldsymbol{X}[x$, $y, z]^{\mathrm{T}}$, where $x(0 \leq x \leq 1)$ is the probability that enterprises will actively abide by the regulations and follow the government strategy for environmental governance, $y(0 \leq y \leq 1)$ is the probability that the government will actively govern environmental problems, and $z(0 \leq z \leq 1)$ is the probability that the public will choose to positively participate in environmental governance. The step size of the simulation represents the dynamic evolution process of system $(K)$. Similar to equilibrium point $I_{1}$, the dynamic evolution of system $(K)$ at points $I_{2}, I_{5}$, and $I_{6}$ is shown in Figures $3-$ and 5 of Appendix A.

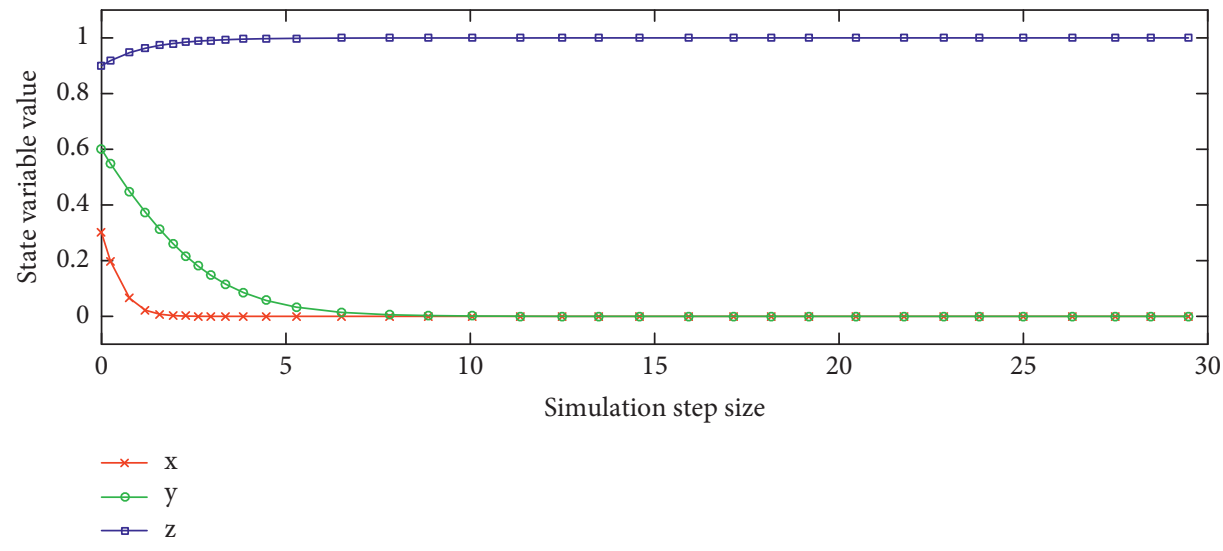

FIGURE 3: Dynamic evolution of system $(K)$ at equilibrium point $I_{2}$.

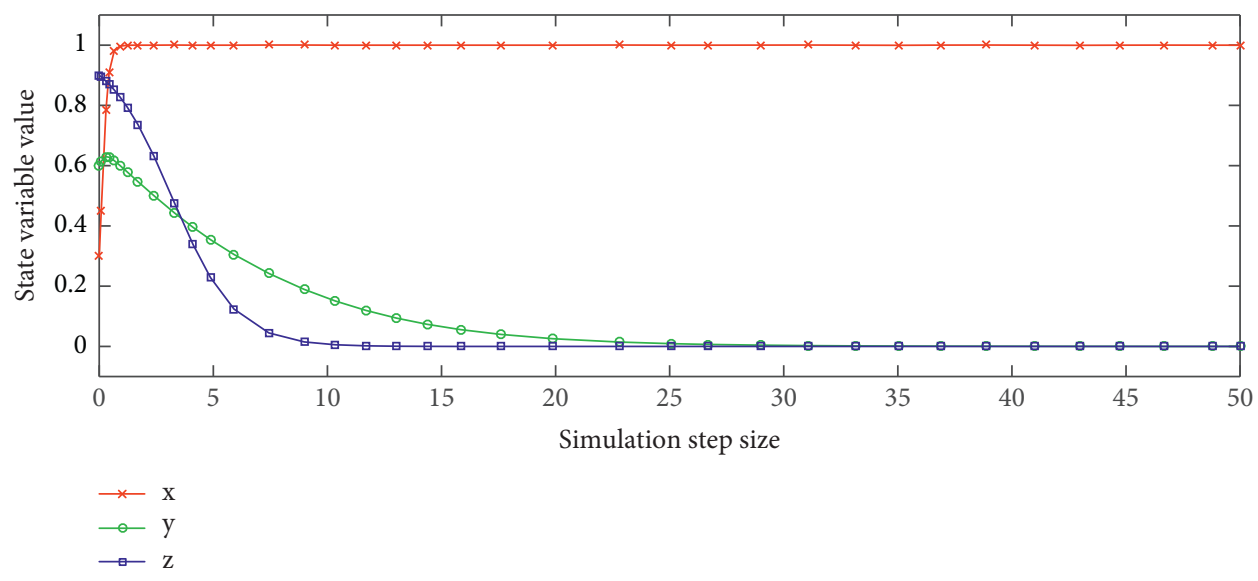

Figure 4: Dynamic evolution of system $(K)$ at equilibrium point $I_{5}$. 


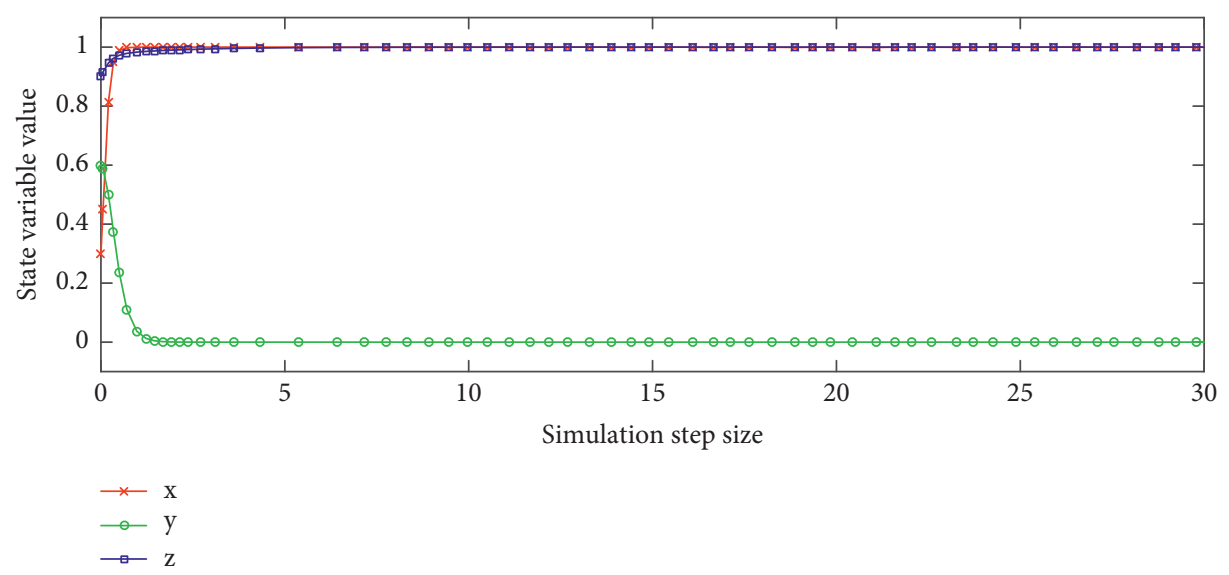

FIGURE 5: Dynamic evolution of system $(K)$ at equilibrium point $I_{6}$.

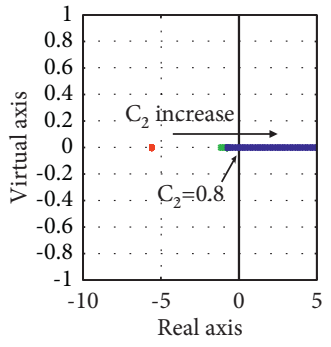

(a)

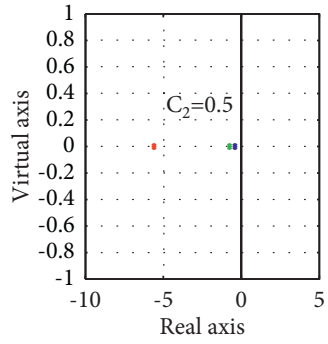

(b)

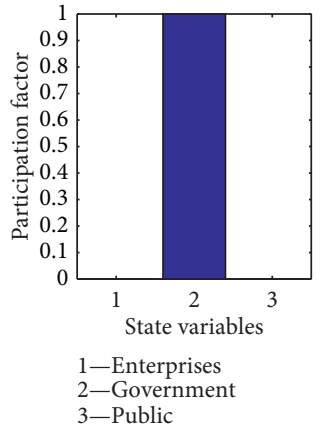

(c)

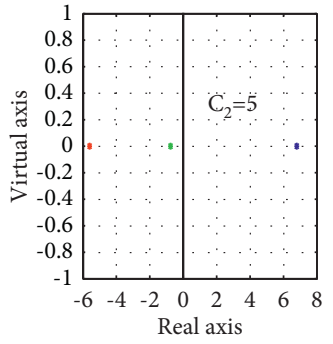

(d)

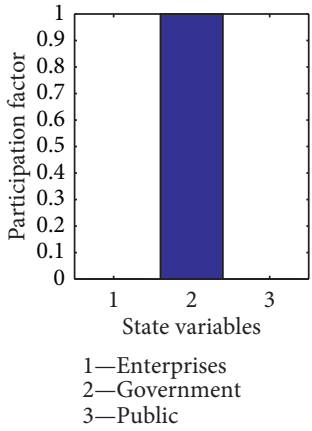

(e)

Figure 6: The influence of political cost $C_{2}$ of $I_{1}$ on the stability of system $(K)$. Annotation: Figures 6(a), 6(b), and 6(d) plot the root locus of system $(K)$ when $C_{2}$ takes different values (continuously varying or fixed), where the horizontal axis represents the real part of the system feature root, and the vertical axis represents the imaginary part of the system feature root. Figures 6(c) and 6(e) plot the participation factors of the three state variables in system $(K)$ when $C_{2}$ takes different values. The three state variables are enterprises, government, and the public. Similar to equilibrium point $I_{1}$, the influence of political cost $C_{2}$ of $I_{2}, I_{5}$, and $I_{6}$ on the stability of system $(K)$ is shown in Figures 7-9 of Appendix A.

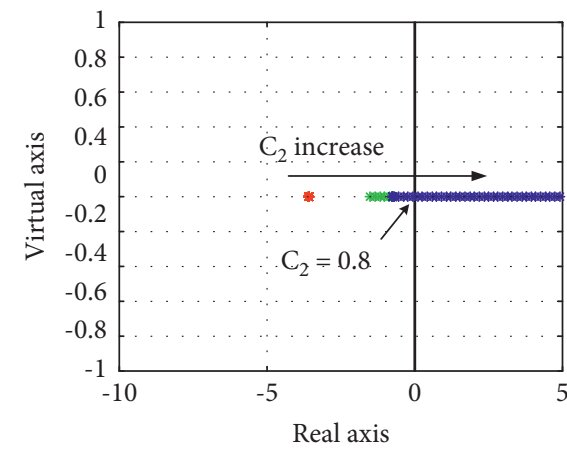

(a)

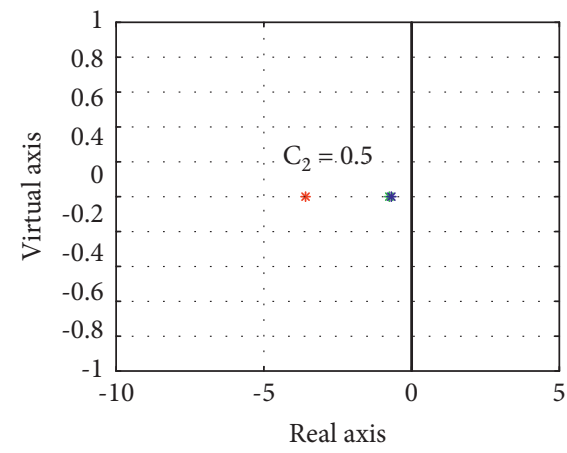

(b)

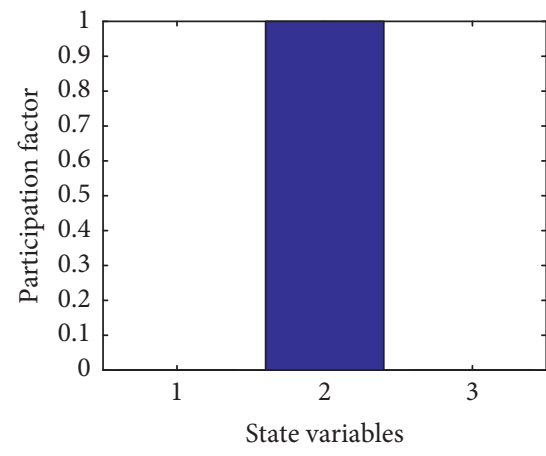

1-Enterprises

2-Government

3-Public

FIgURE 7: Continued. 


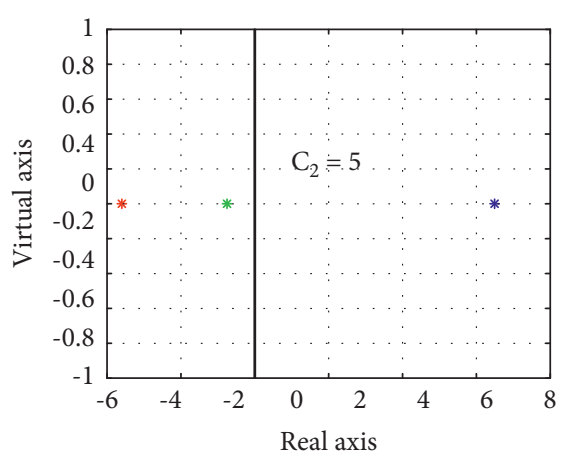

(d)

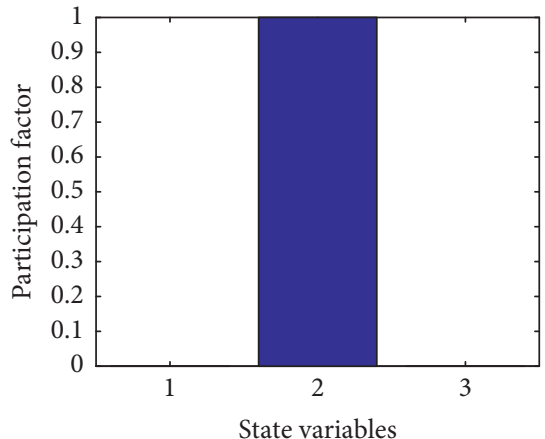

1-Enterprises

2-Government

3-Public

FIgUre 7: The influence of political cost $C_{2}$ of $I_{2}$ on the stability of system $(K)$.

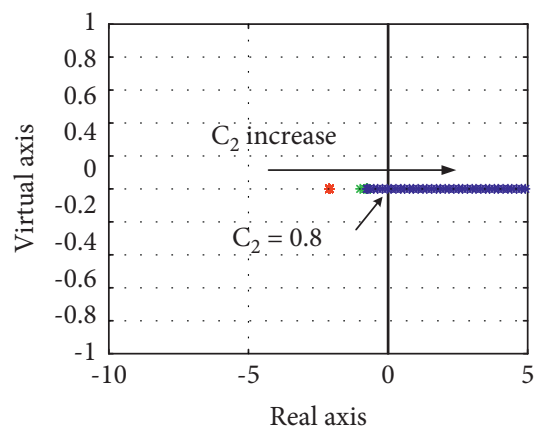

(a)

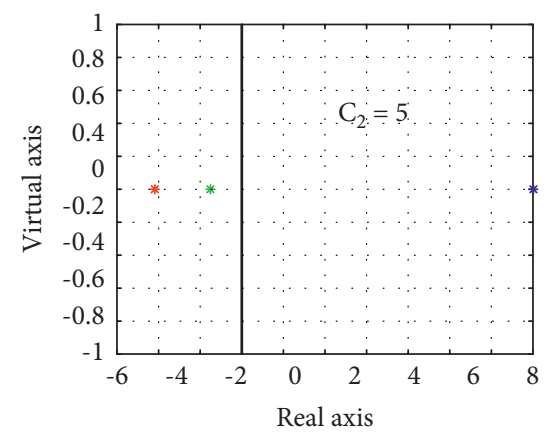

(d)

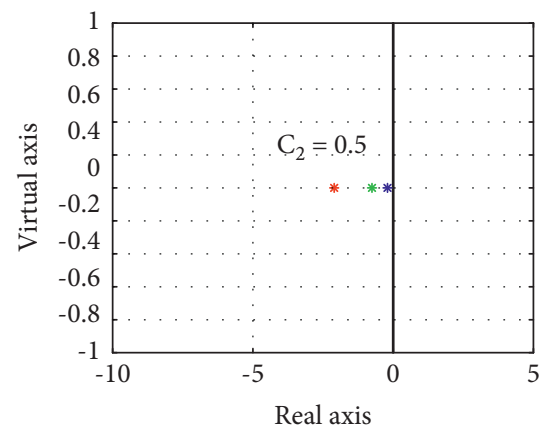

(b)

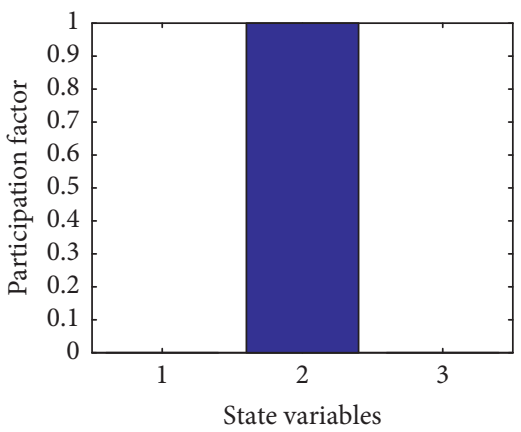

1-Enterprises

2-Government

3-Public

(c)

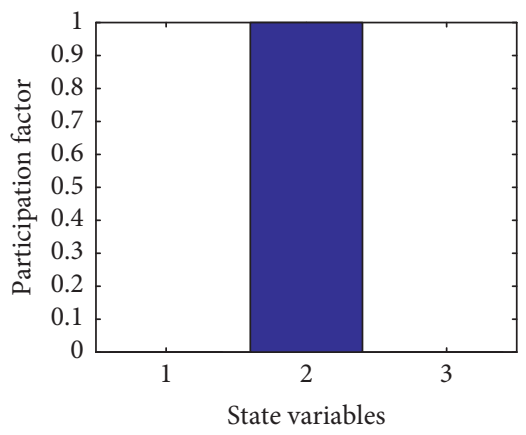

1-Enterprises
2-Government
3-Public

(e)

FIgUre 8: The influence of political cost $C_{2}$ of $I_{5}$ on the stability of system $(K)$.

factors, as well as the stable value range for a given parameter with regard to the stability of the whole system.

By referring to the analysis above, this paper examined two cases of political costs by letting $C_{2}$ take a value of either 0.5 or 5 . As such, the participation of enterprises, governments, and the public can be analyzed when the system is stable and unstable. Figure 6(b) shows the root locus of the system when $C_{2}=0.5$. It can be seen that the 


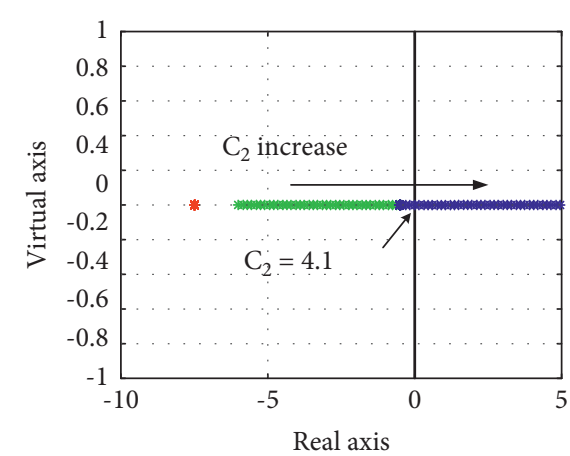

(a)

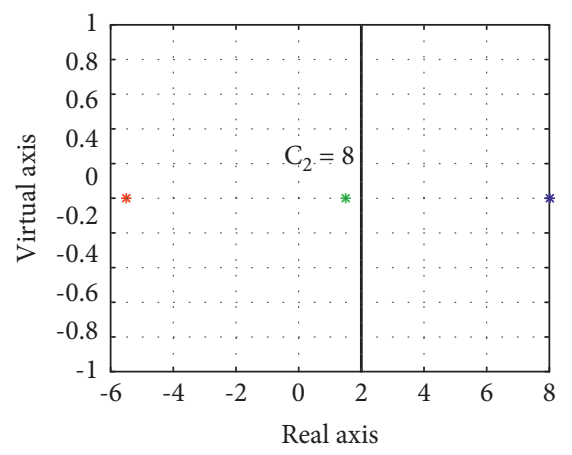

(d)

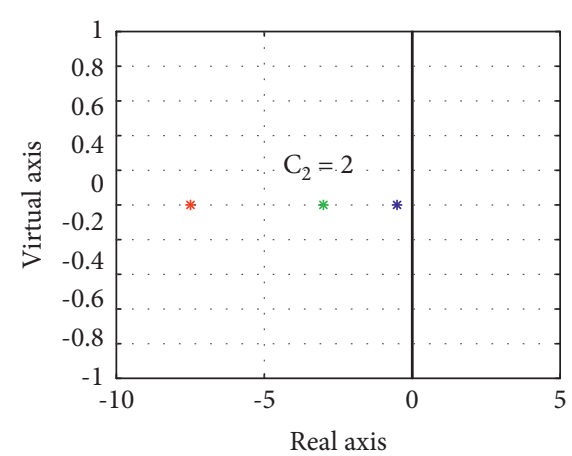

(b)

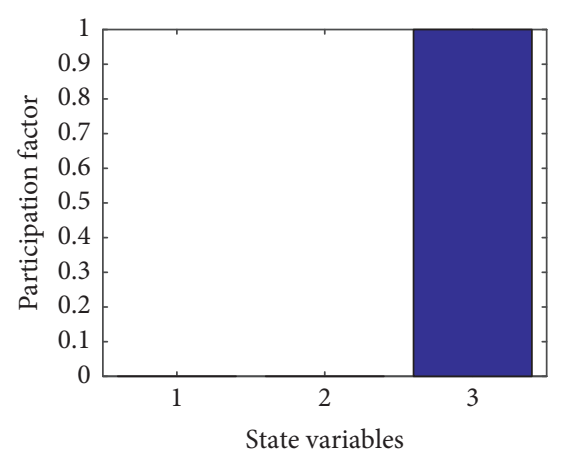

1-Enterprises

2-Government

3-Public

(c)

FIgURE 9: The influence of political cost $C_{2}$ of $I_{6}$ on the stability of system $(K)$.

three eigenvalues of the system remain in the left halfplane, which indicates that the system can operate stably under this value. The most active participant in the game system is the government, as shown in Figure 6(c), which indicates that regulating governmental behavior can play a decisive role in the stability of the system. Similarly, Figure 6(d) shows the root locus of the system when $C_{2}=5$. It can be seen that the three eigenvalues of the system are not in the area of the left half-plane at this time. This indicates that the system cannot operate stably under this value. Figure 6(e) shows that the most active participant in the game theory is the government, which indicates that regulating governmental behavior can play a decisive role in the stability of the system.

From the stability analysis presented above, all of the behavioral strategies that the three parties engaged in were negative in this stage, and such strategies included regulatory violations by enterprises, negative governance on the part of the government, and negative public participation. In this situation, the system's stability domain is very small when political cost $C_{2}$ changes. Under this combination of behavioral strategies, political cost $C_{2}$ hurts the system, which represents a political cost input. Therefore, the above research results show that the stability domain of the system can only allow a low level of consumption in respect to the political cost (input) when all three participants engage in negative behavior. Once the level of consumption is too large (i.e., greater than 0.8), the system loses its stability and becomes unstable. When the environmental governance system is in an unstable state, any interference from the participants leads to disorder within the system. Based on the aforementioned participation factor analysis, irrespective of whether the system is in a stable or unstable state, the government has the greatest impact on the system's state in the game system. In other words, the weaker the government's negative governance behavior, the stronger the stability of the system under this equilibrium point. In addition, the system will be more resistant to interference from other participants. On the contrary, the stronger the government's negative governance behavior, the weaker the stability of the system. Furthermore, the system will be less resistant to interference from other participants. Therefore, it can be concluded that the key to maintaining system stability under this equilibrium point is to reduce the consumption of political costs (input). The stability of the system will only be ensured if the cost consumption is controlled and maintained within a certain range.

5.2.2. Stability of $I_{3}$. According to the initial values described in Table 8, the calculation shows that $I_{3}$ satisfies $a-c<0-d$ $<0, f+g<0$. Furthermore, according to the game equilibrium analysis, equilibrium point $I_{3}$ is asymptotically stable at 
this time. Similarly, we set the initial values of equilibrium point $I_{7}$, which is shown in Table 9 of Appendix B. In order to verify the accuracy of the small-signal model, the initial values of $x, y$, and $z$ were selected randomly. By taking $x=0.3, y=0.6$, and $z=0.9$ as an example, this paper used MATLAB to create the dynamic evolution diagram of system $(K)$, which is shown in Figure 10. It can be seen that the final steady-state values of $x, y$, and $z$ are $[0,1,0]$ under the initial parameters. This means that the final stable state of system $(K)$ reaches equilibrium point $I_{3}(0,1,0)$ based on these parameters. This further verifies the accuracy of the small-signal model. It is worth mentioning that the initial values of $x, y$, and $z$ are random; that is, the final dynamic evolution result will be the same if other values are assigned randomly.

In view of the accuracy of the small-signal model presented above, it was necessary to measure and analyze the political cost at balanced point $I_{3}$. Therefore, we selected the political cost of the government's environmental governance $C_{2}$ as a parameter in order to analyze the stability of the system. The process of analyzing the influence of political cost $C_{2}$ on the stability of system $(K)$ is shown in Figure 12.

By taking the initial values shown in Table 8 , this paper gradually increased the value of political cost $C_{2}$ from 0 to 10 in an increased step size of 0.1 . The root locus of the system is shown in Figure 12(a). It can be seen that system $(K)$ is always stable with the increase in political cost $C_{2}$. Furthermore, the stability of system $(K)$ increases with the increase in political cost $C_{2}$. In addition, $C_{2}$ is assigned a value of 0 or 10 while maintaining other parameters, and the conclusion can be verified. This shows that after the calculation, the two values of $C_{2}$ satisfy the inequality $a-c<0, \quad-d<0, f+g<0$. Based on the equilibrium analysis of game theory, it can be seen that equilibrium point $I_{3}$ at this time is the convergence point, and it is asymptotically stable. Therefore, the stable region of political cost $C_{2}$ is from 0 to 10 . Moreover, with the increase in the value of $C_{2}$, the stability of the system increases. In other words, the system becomes more stable as the value of $C_{2}$ increases.

Based on the above analysis, this paper assigned a value of 0.5 to political cost $C_{2}$ so that the participation of enterprises, governments, and the public could be analyzed. Figure 12(b) shows the root locus of the system when $C_{2}=0.5$. It can be seen that the three eigenvalues of the system remain in the left half-plane, which indicates that the system can operate stably under this value. The most active participant in the game system is the public, as shown in Figure 12(c), which indicates that regulating the public's behavior can play a decisive role in the stability of the system.

From the stability analysis outlined above, the behavioral strategies of the three parties include regulatory violations by enterprises, positive governance on the part of the government, and negative public participation. In this situation, the domain of the system's stability is large when political cost $C_{2}$ changes. Under this combination of behavioral strategies, the influence of political cost $C_{2}$ on the system has a positive effect, and it represents benefits that are associated with political influence. Therefore, the results outlined above show that, irrespective of the value of political cost $C_{2}$, the system state is in a stable region, and any interference from the participants will not affect the system. Based on the aforementioned participation factor analysis, the public has the greatest impact on the system state under this combination of behavioral strategies. In other words, the weaker the public's negative participation behavior, the stronger the stability of the system under this equilibrium point, and the system will be more resistant to interference from other participants.

5.2.3. Stability of $I_{8}$. According to the initial values described in Table 10, after the calculation, it can be seen that $I_{8}$ satisfies $-a<0, \quad-d-e+f<0,-f-g<0 . \quad$ Furthermore, according to the game equilibrium analysis, equilibrium point $I_{8}$ is asymptotically stable at this time. Similarly, we set the initial values of equilibrium point $I_{4}$, which is shown in Table 11 of Appendix C. In order to verify the accuracy of the small-signal model, the initial values of $x, y$, and $z$ were selected randomly. By taking $x=0.3, y=0.6$, and $z=0.9$ as an example, this paper used MATLAB to create a dynamic evolution diagram of system $(K)$, which is shown in Figure 14. It can be seen that the final steady-state values of $x, y$, and $z$ are $[1,1,1]$ under the initial parameters. This means that the final stable state of system $(K)$ reaches equilibrium point $I_{8}(1,1,1)$ based on these parameters. Moreover, this also verifies the accuracy of the small-signal model. It is worth mentioning that the initial values of $x, y$, and $z$ were random; that is, the final dynamic evolution result will be the same if other values are assigned randomly.

Having verified the accuracy of the small-signal model described above, it was necessary to measure and analyze the political cost at balanced point $I_{8}$. Therefore, we selected the political cost of the government's environmental governance $C_{2}$ as a parameter in order to analyze the stability of the system. The process of analyzing the influence of political cost $C_{2}$ on the stability of system $(K)$ is shown in Figure 16.

By taking the initial values shown in Table 10, this paper gradually increased the value of political cost $C_{2}$ from 0 to 10 in an increased step size of 0.1 . The root locus of the system is shown in Figure 16(a). It can be seen that system $(K)$ gradually moves from unstable to stable with the continuous increase in political cost $C_{2}$. At the same time, the value of $C_{2}$ is 1.1 at the critical stable point. Therefore, when political cost $C_{2}$ is more than 1.1 , system $(K)$ has small-signal stability. In addition, if the value of $C_{2}$ is 1.1 and other parameters are maintained, the conclusion can be verified. This shows that after the calculation, $-a<0,-d-e+f<0,-f-g<0$. Based on the equilibrium analysis of the game theory model, it is evident that equilibrium point $I_{8}$ at this time is a saddle point and it is unstable. Therefore, political cost $C_{2}$ is stable in the region defined by 1.1 to 10 . Moreover, with the increase in the value of $C_{2}$, the stability of the system will increase.

By referring to the analysis above, this paper examined two cases of the political costs by letting $C_{2}$ take a value of either 0.5 or 5 . Thus, the participation of enterprises, governments, and the public can be analyzed when the system is stable and unstable. Figure 16(b) shows the root 
TABLE 8: Parameter values of all variables at balanced point $I_{3}$.

\begin{tabular}{lccccccc}
\hline Variable & Parameter value & Variable & Parameter value & Variable & Parameter value & Variable & Parameter value \\
\hline$C_{1}$ & 1 & $\alpha$ & 0.6 & $A$ & 0.1 & 1 & $L_{1}$ \\
$C_{2}$ & 0.5 & $\beta$ & 0.5 & $E_{1}$ & 2 & $L_{2}$ & 2 \\
$C_{3}$ & 2 & $\theta$ & 0.5 & $E_{2}$ & 2 & $L_{3}$ & $F_{1}$ \\
$C_{4}$ & 2 & $P$ & 1 & $E_{3}$ & 1 & $F_{2}$ & 3 \\
$R_{1}$ & 5 & $T$ & 3 & $E_{4}$ & 0.5 & \\
$R_{2}$ & 10 & & & & & \\
\hline
\end{tabular}

TABLE 9: Parameter values of all variables at balanced point $I_{7}$.

\begin{tabular}{lccccccc}
\hline Variable & Parameter value & Variable & Parameter value & Variable & Parameter value & Variable & Parameter value \\
\hline$C_{1}$ & 1 & $\alpha$ & 0.6 & $A$ & 0.5 & $L_{1}$ & 2 \\
$C_{2}$ & 2 & $\beta$ & 0.5 & $E_{1}$ & 1 & $L_{2}$ & $L_{3}$ \\
$C_{3}$ & 2 & $\theta$ & 0.5 & $E_{2}$ & 2 & $F_{1}$ & 5 \\
$C_{4}$ & 2 & $P$ & 2 & $E_{3}$ & 1 & $F_{2}$ & 3 \\
$R_{1}$ & 10 & $T$ & 2 & $E_{4}$ & 0.5 & \\
$R_{2}$ & 10 & & & & & \\
\hline
\end{tabular}

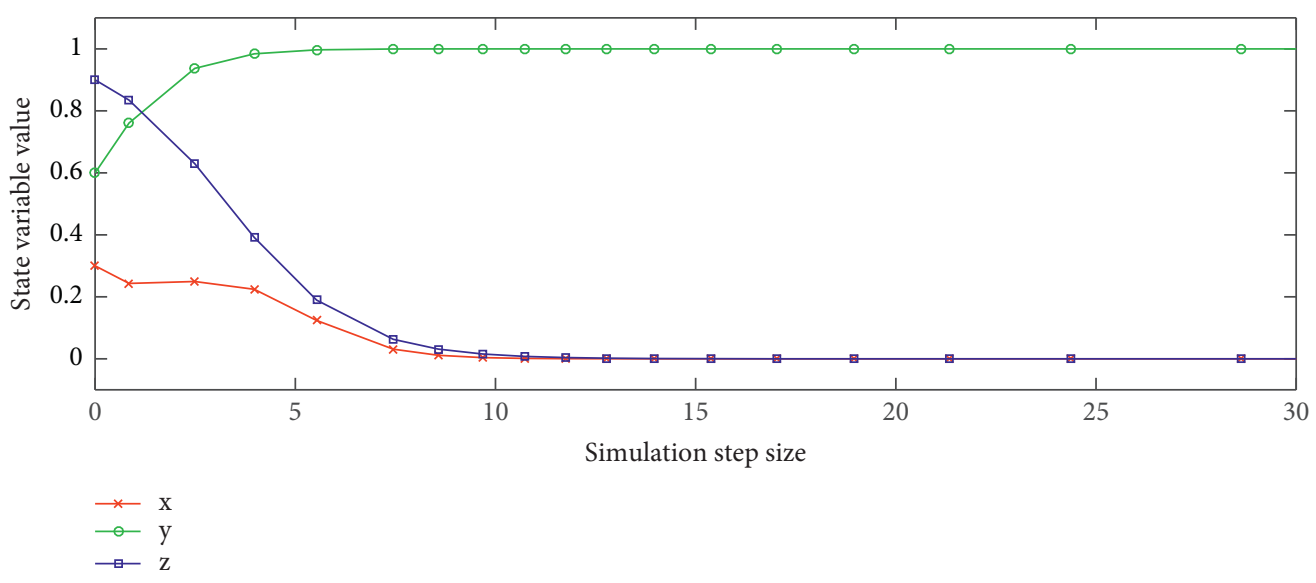

Figure 10: Dynamic evolution of system $(K)$ at equilibrium point $I_{3}$. Annotation: Similar to equilibrium point $I_{3}$, the dynamic evolution of system $(K)$ at point $I_{7}$ is shown in Figure 11 of Appendix B.

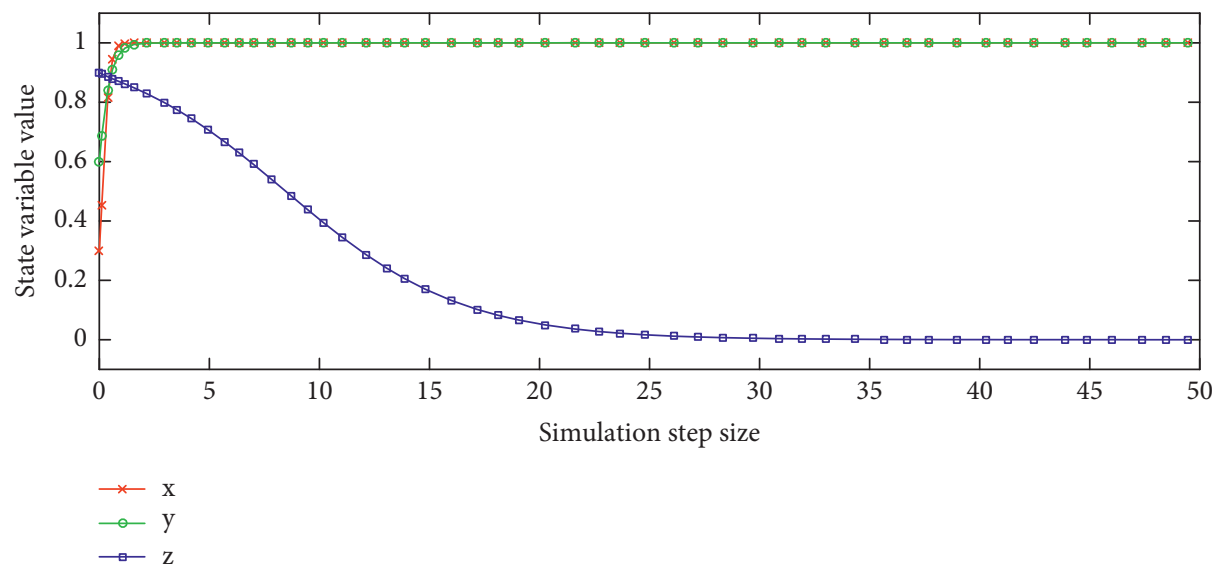

Figure 11: Dynamic evolution of system $(K)$ at equilibrium point $I_{7}$.

locus of the system when $C_{2}=0.5$. It can be seen that the three eigenvalues of the system remain in the left halfplane, which indicates that the system can operate stably under this value. The most active participant in the game system is the public, as shown in Figure 16(c), which indicates that regulating the public's behavior can play a 


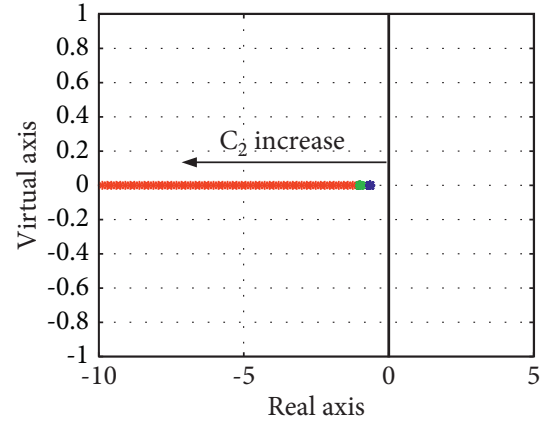

(a)

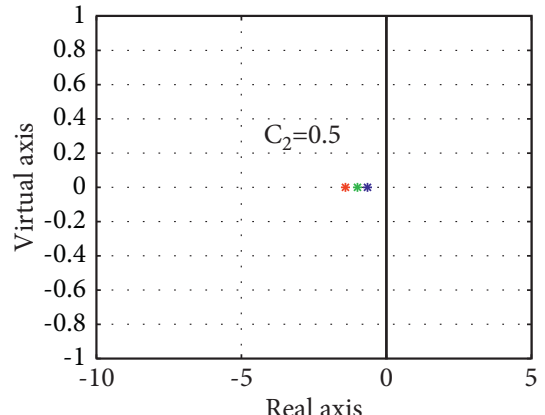

(b)

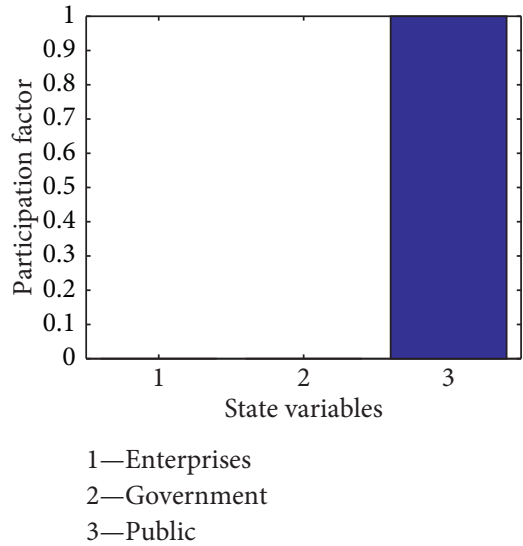

(c)

FIgURE 12: The influence of political $\operatorname{cost} C_{2}$ of $I_{3}$ on the stability of system $(K)$. Annotation: Similar to the equilibrium point $l_{3}$, the influence of the political cost $\mathrm{C} 2$ of $l_{7}$ on the stability of system $(\mathrm{K})$ is shown in Figure 13 of Appendix B.

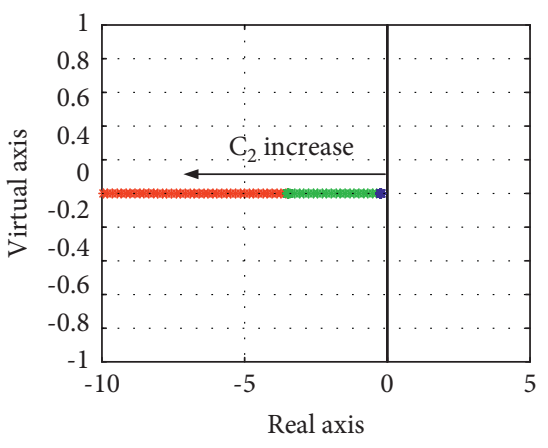

(a)

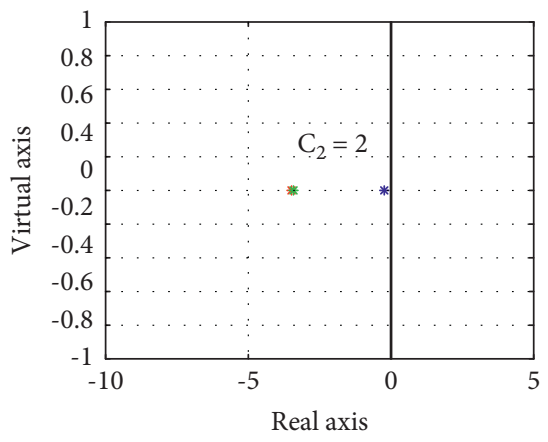

(b)

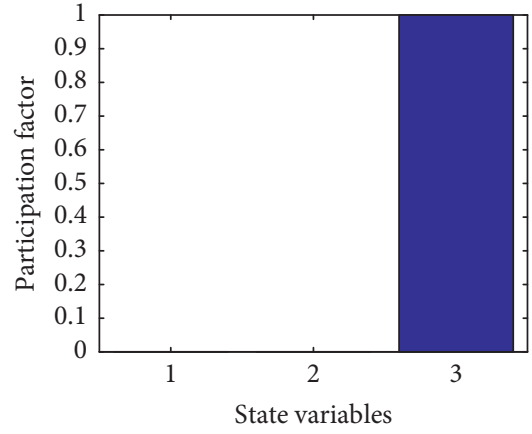

1-Enterprises

2-Government

3-Public

(c)

FIgURE 13: The influence of political cost $C_{2}$ of $I_{7}$ on the stability of system $(K)$.

TABLE 10: Parameter values of all variables at balanced point $I_{8}$.

\begin{tabular}{lccccccc}
\hline Variable & Parameter value & Variable & Parameter value & Variable & Parameter value & Variable & Parameter value \\
\hline$C_{1}$ & 1 & $\alpha$ & 0.6 & $A$ & 2 & $L_{1}$ & 2 \\
$C_{2}$ & 2 & $\beta$ & 0.5 & $E_{1}$ & 1 & $L_{2}$ & $L_{3}$ \\
$C_{3}$ & 2 & 0 & 0.5 & $E_{2}$ & 2 & $F_{1}$ & 5 \\
$C_{4}$ & 1 & $P$ & 2 & $E_{3}$ & 1 & $F_{2}$ & 3 \\
$R_{1}$ & 10 & $T$ & 2 & $E_{4}$ & 2 & \\
$R_{2}$ & 10 & & & & & \\
\hline
\end{tabular}

TABLE 11: Parameter values of all variables at balanced point $I_{4}$.

\begin{tabular}{lccccccc}
\hline Variable & Parameter value & Variable & Parameter value & Variable & Parameter value & Variable & Parameter value \\
\hline$C_{1}$ & 2 & $\alpha$ & 0.6 & $A$ & 0.5 & $L_{1}$ & 2 \\
$C_{2}$ & 1 & $\beta$ & 0.5 & $E_{1}$ & 1 & $L_{2}$ & 2 \\
$C_{3}$ & 2 & $\theta$ & 0.5 & $E_{2}$ & 2 & $L_{3}$ & $F_{1}$ \\
$C_{4}$ & 0.5 & $P$ & 2 & $E_{3}$ & 1 & $F_{2}$ & 1 \\
$R_{1}$ & 5 & $T$ & 2 & $E_{4}$ & 2 & \\
$R_{2}$ & 10 & & & & & \\
\hline
\end{tabular}




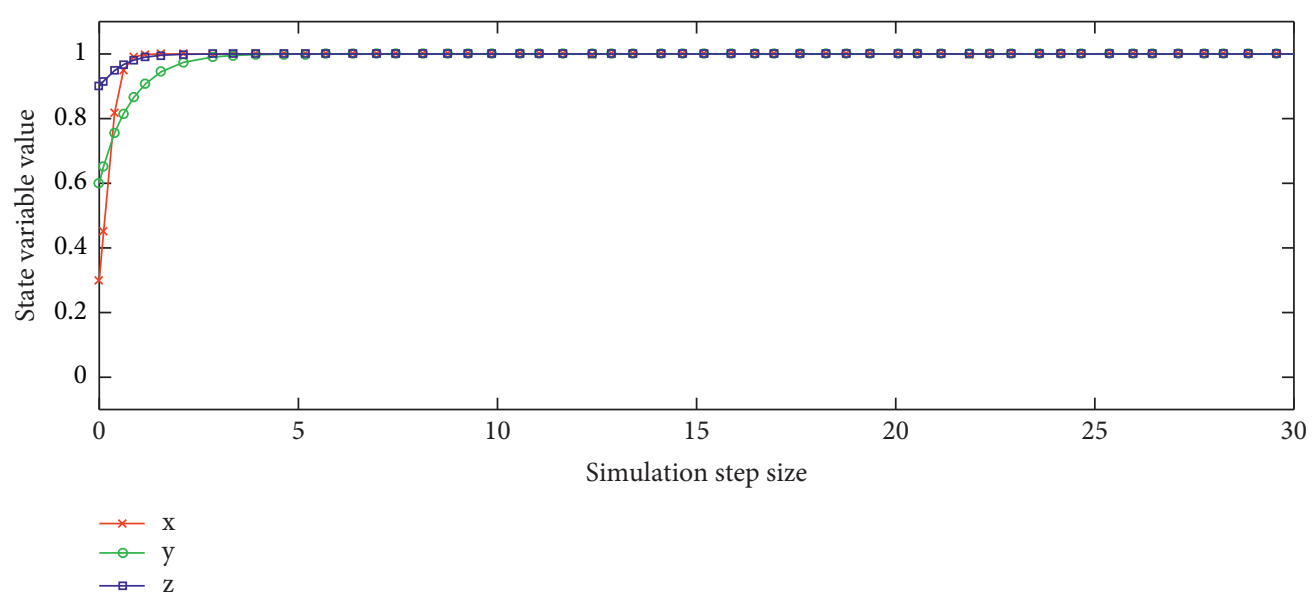

Figure 14: Dynamic evolution of system $(K)$ at equilibrium point $I_{8}$. Annotation: Similar to the equilibrium point $l_{8}$, the dynamic evolution of system $(K)$ at point $l_{4}$ is shown in Figure 15 of Appendix C.

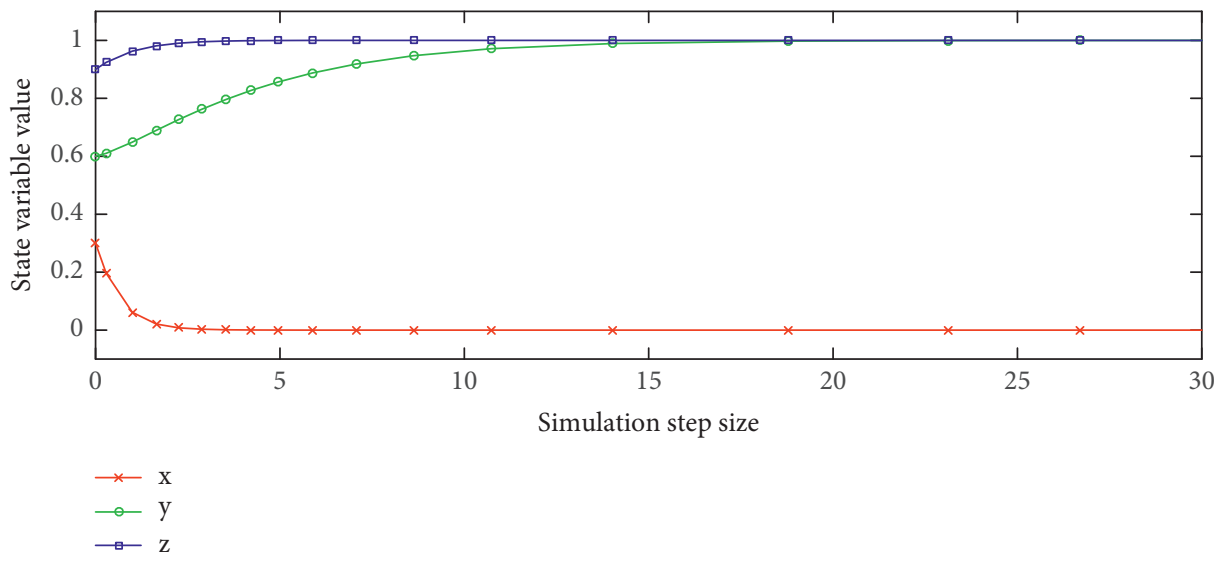

Figure 15: Dynamic evolution of system $(K)$ at equilibrium point $I_{4}$.

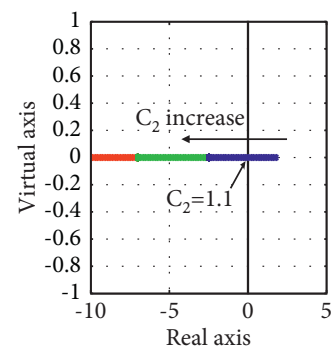

(a)

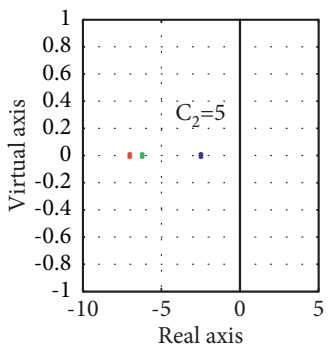

(b)

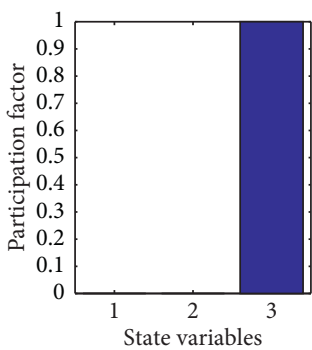
1-Enterprises
$2-$ Government 3-Public

(c)

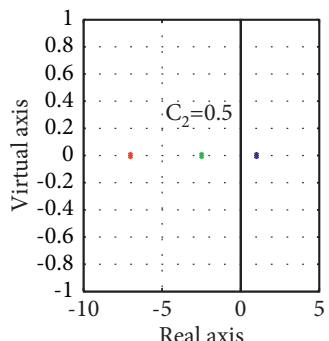

(d)

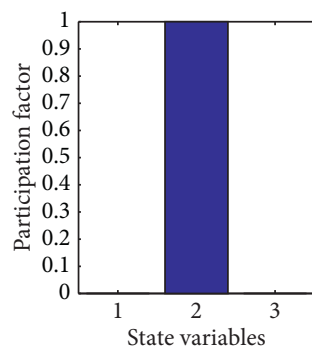

1 -Enterprises 2-Government 3-Public

(e)

FIGURE 16: The influence of political cost $C_{2}$ of $I_{8}$ on the stability of system $(K)$. Annotation: Similar to the equilibrium point I8, the influence of the political cost C2 of I4 on the stability of system $(\mathrm{K})$ is shown in Figure 17 of Appendix C.

decisive role in the stability of the system. Similarly, Figure 16(d) shows the root locus of the system when $C_{2}=5$. It can be seen that, at this time, the three eigenvalues of the system do not remain in the area of the left halfplane. This indicates that the system cannot operate stably under this value. As shown in Figure 16(e), the most active 


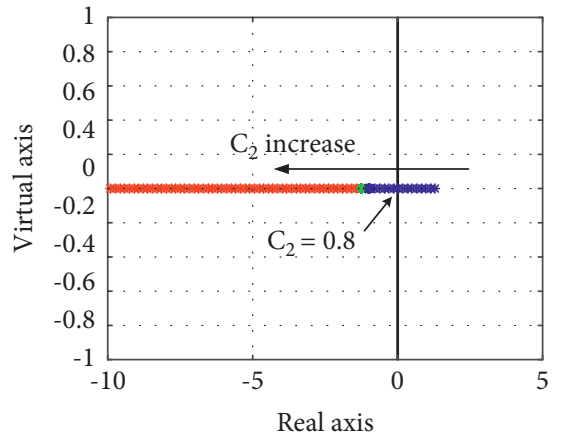

(a)

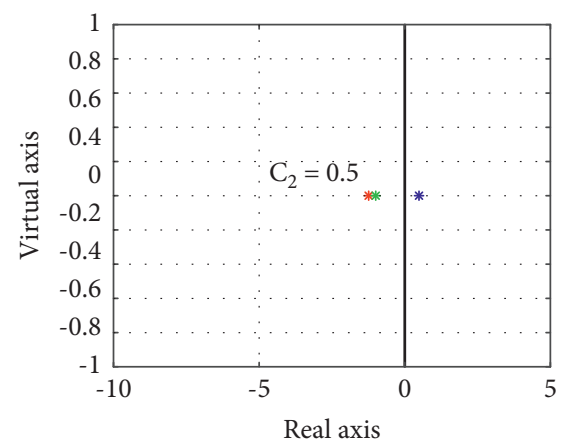

(d)
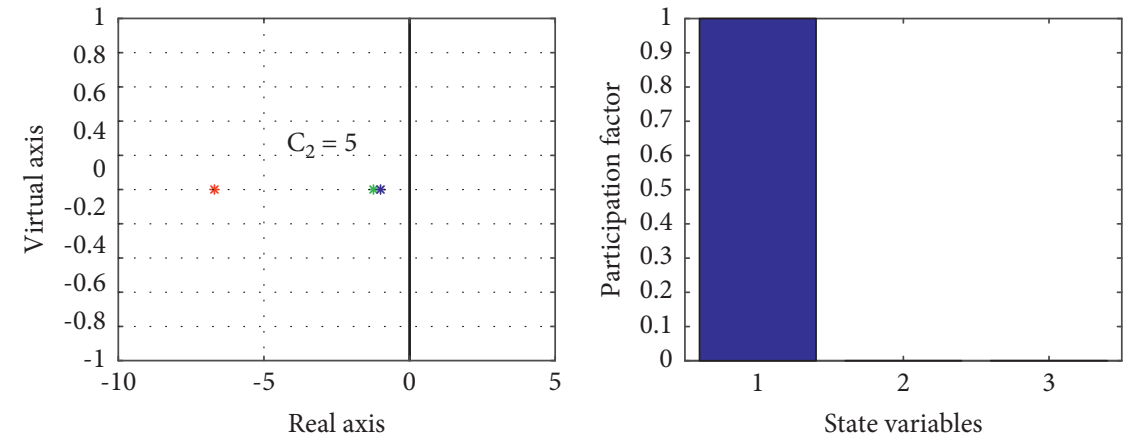

1-Enterprises

2-Government

3-Public

(b)

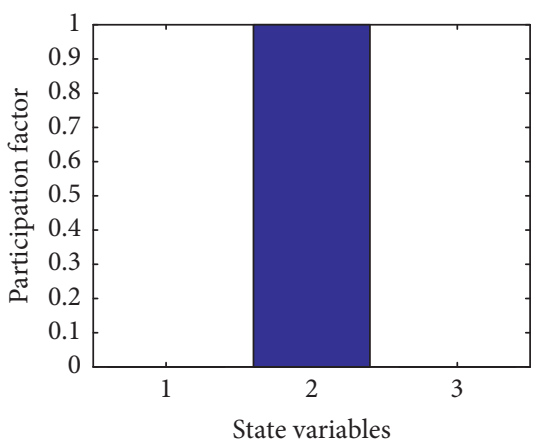

1-Enterprises

2-Government

3-Public

Figure 17: The influence of political cost $C_{2}$ of $I_{4}$ on the stability of system $(K)$.

participant in the game system is the government, which indicates that regulating governmental behavior can play a decisive role in the stability of the system.

From the stability analysis presented above, all of the behavioral strategies that the three entities engaged in were positive in this stage, and such strategies included compliance by enterprises, positive governance of the government, and positive public participation. In this situation, the domain of the system's stability is large when political cost $C_{2}$ changes. Under this combination of behavioral strategies, the influence of political cost $C_{2}$ on the system has a positive effect, and it represents benefits that are associated with political influence. Therefore, the above research results show that the system can maintain a stable state when the system's political cost $C_{2}$ exceeds the value of 1.1. At this time, any interference from the participants will not affect the system. Furthermore, based on the aforementioned participation factor analysis, the public has the greatest impact on the system's state when the system is in a stable state. When the system is in an unstable state, the government has the greatest impact on the system's state. In other words, the stronger the public's positive participation behavior, the stronger the stability of the system under this equilibrium point. In addition, the system will be more resistant to interference from other participants. Meanwhile, the weaker the government's positive governance behavior, the greater the instability of the system. In addition, the system will be less able to resist interference from other participants. Therefore, it can be concluded that the key to maintaining the stability of the system under this equilibrium point is to guide the public's positive participation behavior.

In other words, in the multiparty game, one of the factors affecting the government's strategy is the gain of its positive governance. When the government takes a positive strategy with low gain, it will take a negative governance strategy for enterprises, when political cost consumption increases. Then, the system begins to evolve from a stable state to an unstable state. The benefits come from the participation of enterprises and the public for the government's positive governance, when the political costs are controlled and the government's benefits gradually increase, that is, when the government adopts a positive strategy and the benefits are higher, the government tends more to adopt a positive supervision policy. Then, the system's unstable state will return to stability, the public and enterprises will also choose 
TABLe 12: Dominant participation factors of the system in stable and unstable regions at each equilibrium point.

\begin{tabular}{lccc}
\hline No. & Equilibrium point & Dominant participation factors in the stability domain & Dominant participation factors in the instability domain \\
\hline 1 & $I_{1}(0,0,0)$ & Government & Government \\
2 & $I_{2}(0,0,1)$ & Government & Government \\
3 & $I_{3}(0,1,0)$ & Public & - \\
4 & $I_{4}(0,1,1)$ & Enterprises & Government \\
5 & $I_{5}(1,0,0)$ & Government & Government \\
6 & $I_{6}(1,0,1)$ & Public & Government \\
7 & $I_{7}(1,1,0)$ & Public & - \\
$\mathbf{8}$ & $\mathbf{I}_{8}(\mathbf{1}, \mathbf{1}, \mathbf{1})$ & Public & Government \\
\hline
\end{tabular}

The optimal balance point is $I_{8}$, which can contribute to ensuring the stability of the system, and it is indicated using bold.

rational behavior, and the loss of political costs will be stopped in time. Conversely, when the gain of active government governance is smaller, it indicates that government governance is subject to resistance from enterprises and a lack of public support, and it will tend to choose a negative governance strategy. In this case, the government enterprise public evolutionary game will gradually stabilize in the strategy combination of active governance, compliance, and active participation. This also provides a feasible solution to the information asymmetry problem of environmental governance, that is, valuing political costs, increasing public participation, and improving the benefits of active government governance.

\section{Conclusions}

\subsection{Main Conclusions and Policy Implications}

(1) Based on the reality of environmental governance, this paper put forward a basic assumption for environmental governance in relation to public participation. In the meantime, using game equilibrium analysis, small-signal model analysis, and numerical simulation technology, this paper carried out an equilibrium analysis of each equilibrium point and determined the evolutionary mechanism of the political cost at each equilibrium point. From the analysis outlined above, we clarified the analysis of the evolutionary game process and the measurement of political costs of the three entities of governance. Finally, the results for each balanced point were collected during the process of the game (see Table 12 for details). The dominant participation factors, which maintain the stability of the system, were different at each equilibrium point. However, the results indicate that it is the government's governance behavior which causes system instability, as shown by the leading participation factors at different stages. Therefore, in the evolutionary game of the environmental governance system that mainly considers political costs, it is particularly important to consider the choice of the government's governance behavioral strategies, as this has a significant effect on the stability of the whole system. Furthermore, at optimal balance point $I_{8}$, the dominant participation factor is the public's participation behavior, which can contribute to ensuring the stability of the system.

At the same time, when the unstable system dominant participant factor is the government, it is necessary for the government to pay attention and reduce political cost consumption in a timely manner. In addition, positive governance strategies should be implemented to achieve governance system stability, which is a time-consuming and complex process. The local governments should develop an awareness of political costs, establish political cost control mechanisms and automatic identification and monitoring mechanisms, make good use of the emotional buffer zone in the virtual space of the network, and pay attention to the early warnings at each stage of environmental remediation, in order to introduce and adopt governance policies promptly to control the continuously rising consumption of political costs.

(2) The governance system will experience a phase of system stagnation when it develops to $I_{2}(0,0,1)$, which is the beginning of a significant loss of political costs. Local governments are both stable and unstable domain participants because local governments tend to form their own preferences for environmental governance policy implementation based on local economic benefits, taxes, and governance costs. When economic benefits are consistent with local environmental governance preferences, local governments will be motivated to implement governance policies while ignoring political costs. However, when their preferences are inconsistent, local governments tend to adopt incomplete implementation and avoid taking responsibility for environmental governance. Political resources occupied by politically active entities to govern the environment are limited, and incomplete implementation and avoidance of responsibility will increase the consumption of political costs, implying that the government's authority and legitimacy will be reduced. This will have a negative impact on social stability, the business environment, and policy implementation. Additionally, it will hinder the development of the local economy. This stagnation phase requires the dominant factor in the unstable domain to adopt an effective strategy to prevent 
the"ripple effect" of excessive political cost consumption.

Therefore, it is necessary that officials in the implementation department enhance their professionalism and equip themselves with professional instruments and technical facilities to facilitate their collection and analysis of environmental governance monitoring. At the same time, local governments can use these measurement and control methods to measure the size of the political cost of environmental governance in the region and use it as an important basis for measuring and monitoring the consumption of political costs in relation to environmental governance. Furthermore, this helps local governments to make accurate predictions and preparations and to take quick responses and decisions in addressing the possible issues in environmental governance on the basis of controlling political costs. Thus, all aspects of the governance system can quickly reach a stable and ideal equilibrium and avoid social risks.

(3) At ideal equilibrium point $I_{8}$ (the optimal equilibrium point), the dominant participation factor that maintains the system in a stable domain is public behavior, which is the core element that affects the consumption of political costs. To some extent, the public's active participation has a substitution effect on the local government's environmental remediation. The public should strengthen their own environmental literacy and rationally defend their environmental rights and interests; that is, the public should actively participate in environmental governance and protection supervision while following the principle of public rationality. As for the government, the signal of this equilibrium point is a warning that reminds officials who have taken a chance not to engage in desperate efforts to conceal information asymmetry, and it is also a reassurance for government officials to boldly deal with the management of environmental issues. In addition, this equilibrium gives other groups, such as businesses and the public, a political environment in which they can better conduct criticism and monitoring.

$l_{8}$ brings about a positive tripartite effect on"government-enterprise-public"; the increase of government benefits from active governance will further promote the government to strengthen the active governance strategy and stabilize on the strategy of active governance without any incentive to change. Thus, the political cost is consumed at a lower rate, and the system gradually stabilizes. However, it also has a negative impact on local economic development (e.g., lower business income and lower tax revenue). Therefore, it is necessary to explore the appropriate path to internalize the externalities of environmental governance to solve the problem, such as using the environmental tax paid for pollution regulation and treatment, transferring funds to reward enterprises that actively reduce emissions to improve pollution reduction equipment, reducing the overall tax burden of enterprises, building a complete environmental monitoring system and monitoring intelligence information system, and forming an interactive and circular chain of "enterprise subsidies-technological innovation-improve total factor productivity-economic growth-drive local governments to increase investment in environmental management." It is necessary to increase public perception of environmental governance to determine the level of subsidies, improve public psychological intervention mechanisms, and enhance rational public perceptions of"environmental governance" through various channels and platforms, such as official media and social organizations, while correcting public bias and beliefs and promoting value recognition and public psychological gain [75]. It is also important to develop cross-organizational cooperation to broaden public participation channels, reasonably design the form of participation, efficiently address public letters, visits, and complaints, and reduce the cost of public participation.

(4) In the evolutionary game process of the governance system, when the political cost of environmental governance is extremely depleted, the public relinquishes consideration of economic interests, employment, and other factors and instead voices its demand to address environmental interests. The public will then choose the behavior strategy of negative participation, so that the governance system becomes unstable. In terms of local environmental remediation, there is usually a point of $I_{3}(0,1,0)$, when the extreme depletion of political costs shows an inverted U-shaped apex position, and the local government loses the role of the leading participatory factor in unstable domains. If no further measures are taken, the whole governance system may become unstable. This also shows that in the process of environmental governance policy implementation, local governments should take measures in financial investment, taxation, and supervision and punishment mechanisms, but if the political costs are ignored at the critical moment, it will also lead to policy failure. Additionally, when the local government is under the control of political costs, the local government will also bring about a failure in policy if there is overimplementation. For the public, the higher the government reward, the more inclined the public action strategy to choose active participation. Moreover, stricter government environmental regulation policies make it more likely that the public will choose a negative participation strategy. Environmental regulation has a certain "crowding-out effect" on public participation, leading to lower political costs and thus systemic instability [76]. 
Local government strategies to control political costs should be constantly adjusted according to the development of environmental remediation events and the evolution of the governance system. Local governments should moderate the intensity of environmental assessment, moderately control the administrative accountability of officials, gradually increase the proportion of public reputation evaluation, prudently assess whether policy goals match political costs, and reasonably delineate the boundary between social supervision and government regulation to prevent policy overimplementation or policy overspill. It is also important to address the one-way linkage of the traditional governance model which focuses only on policy inputs and outputs.

6.2. Limitations and Future Research. In environmental governance, political cost control strategies have to be considered if we want to achieve real effectiveness and"good governance." In the future, we will continue to study the issue of the practical question surrounding political costs, their use, measurement, and operation, by referring to actual cases and using the actual measurement values of political costs within the context of environmental issues. These can be deduced from the evaluation index system, and it is possible to embed the mathematical models of the evolutionary game and small signals to derive the control process associated with political costs relating to environmental issues. The results of this article remind the government to minimize political costs and maximize the political impact. Additionally, the findings remind the government to determine the stage of local governance through field research, collecting data and information, clarifying the situation of each stakeholder in this stage of governance, investigating the data and parameters involved, organizing the relevant data and information using scientific methods and techniques, processing the data, and obtaining the measurement values of each parameter of the environmental governance system in this stage while also substituting the measurement values of the parameters into the evolutionary game model and small-signal model. To be more specific, the evolutionary game model and small-signal model should be used to calculate the eigenvalues of the system at each equilibrium point and the political cost should be measured to determine the equilibrium state of the governance system (i.e., whether the equilibrium point is the expected ideal equilibrium point) and whether the political cost exists within the expected ideal value of governance. According to the state of the governance system, we will continue to use theoretical and mathematical analyses to adjust each parameter, introduce relevant policies and regulations, and implement governance measures in a timely pattern to reduce the loss of political costs associated with environmental issues and improve governance performance.

In the environmental governance system, the relationships between the government, enterprises, and the public are constantly being reconstructed and developed interactively. In this article, we focus on the evolution mechanism of political costs in relation to environmental issues under the"full-cycle evolution" and"stage suspension" of the system. However, the actual situation involves many complex interests and a broader time frame. Therefore, it is difficult to address all of the aspects presented in this article. For example, there are repeated alternating links in the governance of environmental entities, and some environmental issues are governed by a new system of horizontal regional or cross-sectoral synergy. We later followed up a case and found that residents who resided in the vicinity of the pollution source, after accepting the guidance of the government and compensation from the enterprise, were very supportive and agreed with its practices. They actively participated in monitoring and managing the environment. However, residents who were based far away from the pollution source carried out illegal protests and started petitions, and the local government had to consume certain political costs to address these issues. The local government has to consume some political costs to deal with new issues within the context of'spatial justice and distributive justice." In the future, we would like to further study the transient dynamics and nonequilibrium dynamics of political costs of environmental issues.

\section{Appendix}

\section{A. Stability Results of $I_{2}, I_{5}$, and $I_{6}$}

In this section, we analyze $I_{2}, I_{5}$, and $I_{6}$ like $I_{1}$ and present the results.

(1) Stability of $I_{2}$

(2) Stability of $I_{5}$

(3) Stability of $I_{6}$

\section{B. Stability Results of $\boldsymbol{I}_{7}$}

In this section, we analyze $I_{7}$ like $I_{3}$ and present the results.

(1) Stability of $I_{7}$

\section{Stability Results of $\boldsymbol{I}_{4}$}

In this section, we analyze $I_{4}$ like $I_{8}$ and present the results.

(1) Stability of $I_{4}$

\section{Data Availability}

No data were used to support this study.

\section{Conflicts of Interest}

The authors declare that they have no conflicts of interest.

\section{Authors' Contributions}

All authors contributed equally to this work. Xintao Li was responsible for reviewing and editing, conceptualization, and methodology. Tongshun Cheng was responsible for validation. Zaisheng Zhang was responsible for supervision. $\mathrm{Li}$ Zhao was responsible for visualization, software, and investigation. All authors read and approved the final manuscript. 


\section{Acknowledgments}

This study was supported by the Tianjin Social Science Foundation of China under grant no. TJGLQN20-001 and Fundamental Research Funds for the Central Universities of China under grant no. 63212079.

\section{References}

[1] T. Shi, S. Yang, W. Zhang, and Q. Zhou, "Coupling coordination degree measurement and spatiotemporal heterogeneity between economic development and ecological environment --Empirical evidence from tropical and subtropical regions of China," Journal of Cleaner Production, vol. 244, pp. 1-11, 2020.

[2] Y. Zhang, Y. Hu, Bo Zhang, Y. Li, X. Zhang, and Y. Xie, "Conflict between nature reserves and surrounding communities in China: an empirical study based on a social and ecological system framework," Glob. Ecol. Conserv.vol. 21, pp. 1-12, 2020.

[3] Z. Ahmed, M. Mansoor Asghar, M. N. Malik, and K. Nawaz, "Moving towards a sustainable environment: the dynamic linkage between natural resources, human capital, urbanization, economic growth, and ecological footprint in China," Resources Policy, vol. 67, Article ID 101677, 2020.

[4] Ministry of Ecology and Environment, PRC, "Report on the State of Environment in China," 2019, http://www.mee.gov. cn/hjzl/tj/201905/t20190529_704850.shtml.

[5] A. V. Pham, "Political risk and cost of equity: the mediating role of political connections," Journal of Corporate Finance, vol. 56, pp. 64-87, 2019.

[6] N. F. Elsie, "The role of environmental values and political ideology on public support for renewable energy policy in Ottawa, Canada," Energy Policy, vol. 134, Article ID 110918, 2019.

[7] R. Saha and P. Mohai, "Historical context and hazardous waste facility siting: understanding temporal patterns in Michigan," Social Problems, vol. 52, no. 4, pp. 618-648, 2005.

[8] S. Oksay and E. Iseri, "A new energy paradigm for Turkey: a political risk-inclusive cost analysis for sustainable energy," Energy Policy, vol. 39, no. 5, pp. 2386-2395, 2011.

[9] X. Net, Compilation of Documents of the 19th National Congress of the Communist Party of China, p. 8, People's Publishing Press, Beijing, China, 2017, http://www.news.cn/ politics/19cpcnc/.

[10] Y. Yan, X. Zhang, J. Zhang, and K. Li, "Emissions trading system (ETS) implementation and its collaborative governance effects on air pollution: the China story," Energy Policy, vol. 138, Article ID 111282, 2020.

[11] D. Easton, The Political System: An Inquiry into the State of Political Science, p. 149, Knopf, New York, NJ, USA, 1953.

[12] H. D. Lasswell, Politics: Who Gets what, when, How, p. 188, Peter Smith Publisher, Gloucester, MA, USA, 1990.

[13] D. Lang, The over Socialized conception of Man, p. 313, Tranaction Publishers, Piscataway, NJ, USA, 2003.

[14] A. Raymond, B. Soutter, and R. Mõttus, "Global warming versus climate change: a replication on the association between political self-identification, question wording, and environmental beliefs," Journal of Environmental Psychology, vol. 69, Article ID 101413, 2020.

[15] O. E. Hughes, Public Management and Administration: An Introductionp. 131, China Renmin University Press, Macmillan Education, London, UK, 2015.
[16] F. Moseley, "The development of Marx's theory of the distribution of surplus-value in the Manuscript of 1861-63," Review of Radical Political Economics, vol. 33, no. 3, pp. 265-271, 2001.

[17] T. Belz, D. von Hagen, and C. Steffens, “Taxes and firm size: political cost or political power?" Journal of Accounting Literature, vol. 42, pp. 1-28, 2019.

[18] D. Jacobs, P. M. Paxton, A. L. Jackson, and C. A. Malone, "Murder, political resources, and women's political success," Social Science Research, vol. 42, no. 2, pp. 513-526, 2013.

[19] N. Myers, "The biodiversity crisis and the future of evolution," Environmentalist, vol. 16, no. 1, pp. 37-47, 1996.

[20] S. Martin, "Governing for sustainability: how research on large and complex systems can inform governance and institutional theory," Environ. Policy Gov.vol. 29, pp. 53-63, 2019.

[21] R. W. Peter, "Environmental governance in motion: practices of assemblage and the political performativity of economistic conservation," World Development, vol. 124, Article ID 104626, 2019.

[22] S. Ranjula Bali, S. K. Uma, and K. Amin, "Regulation, governance and the role of the informal sector in influencing environmental quality?" Ecological Economics, vol. 173, Article ID 106649, 2020.

[23] A. A. Gabriel, Comparative politics - system, process and policy, p. 327, Shanghai Translation Press, Shanghai, China, 1987.

[24] Y.-C. T. Huang and R. D. Brook, "The clean air act," Chest, vol. 140, no. 1, pp. 1-2, 2011.

[25] K. Kang, Y. Zhao, J. Zhang, and Q. Chen, "Evolutionary game theoretic analysis on low-carbon strategy for supply chain enterprises," Journal of Cleaner Production, vol. 7, pp. 230245, 2019.

[26] W. Gu, W. Lirong, W. Zhang, and X. Yan, "Evolutionary game analysis of cooperation between natural resource- and energyintensive companies in reverse logistics operations," International Journal of Production Economics, vol. 4, pp. 218-228, 2019.

[27] Y. Chen, J. Zhang, and P. R. Tadikamalla, "The relationship among government, enterprise, and public in environmental governance from the perspective of multi-player evolutionary game," International Journal of Environmental Research and Public Health, vol. 18, 2019.

[28] L. Lu and D. Chen, "Pollution control effect of local government's environmental regulation strategy: mechanism and empirical test," Collected Essays on Finance and Economics, vol. 12, pp. 104-113, 2019.

[29] J. Sheng, W. Zhou, and B. Zhu, "The coordination of stakeholder interests in environmental regulation: lessons from China's environmental regulation policies from the perspective of the evolutionary game theory," Journal of Cleaner Production, vol. 249, Article ID 119385, 2020.

[30] P. Matjaz and S. Attila, "A double-edged sword: benefits and pitfalls of heterogeneous punishment in evolutionary inspection games," Scientific Reports, vol. 5, Article ID 11027, 2020.

[31] Z. Chu, B. Li, H. Xiao, and L. Lu, "An empirical research on indigenous technological innovation process in shenzhen city of China based on time series model," Journal of Applied Sciences, vol. 13, no. 8, pp. 1245-1250, 2013.

[32] Z. Marinković, N. Ivković, O. Pronić-Rančić, M. Vera, and A. Caddemi, "Analysis and validation of neural network approach for extraction of small-signal model parameters of microwave transistors," Microelectronics Reliability, vol. 53, no. 3, pp. 416-419, 2013. 
[33] A. Surat and P. Robin, "Decision tree-based prediction model for small signal stability and generation-rescheduling preventive control," Electric Power Systems Research, vol. 196, Article ID 107200, 2021.

[34] Q. Roberto, "Improvement of small signal equivalent simulations for power and efficiency matching of GaN HEMTs," Electronics, vol. 10, no. 3, p. 263, 2021.

[35] R. Arsalan and H. D. Taghirad, "Corner stability in nonlinear autonomous systems," Nonlinear Dynamics, vol. 80, no. 1-2, pp. 959-968, 2015.

[36] M. G. Umamaheswari, G. Uma, and L. Annie Isabella, "Analysis and design of digital predictive controller for PFC Cuk converter," Journal of Computational Electronics, vol. 13, no. 1, pp. 142-154, 2014.

[37] M. Antoine, H. Li, X. Zheng, and Y. Yu, "Small-signal model and stability control for grid-connected PV inverter to a weak grid," Energies, vol. 14, no. 13, p. 3907, 2021.

[38] X. Zhu and S. Bruno, "Global sensitivity analysis for stochastic simulators based on generalized lambda surrogate models," Reliability Engineering \& System Safety, vol. 214, Article ID 107815, 2021.

[39] S. Dridi and L. Lehmann, "Environmental complexity favors the evolution of learning," Behavioral Ecology, vol. 27, no. 3, pp. 842-850, 2016.

[40] A. Azadegan, P. C. Patel, A. Zangoueinezhad, and K. Linderman, "The effect of environmental complexity and environmental dynamism on lean practices," Journal of Operations Management, vol. 31, no. 4, pp. 193-212, 2013.

[41] X. Zhu, Q. Yuan, and W. Zhang, "Inventory leanness, risk taking, environmental complexity, and productivity," Journal of Manufacturing Technology Management, vol. 29, no. 7, pp. 1211-1232, 2018.

[42] A. A. Batabyal, "Development, trade, and the environment: which way now?" Ecological Economics, vol. 13, no. 2, pp. 83-88, 1995.

[43] X. D. Diao, S. X. Zeng, C. M. Tam, and V. W. Y. Tam, "EKC analysis for studying economic growth and environmental quality: a case study in China," Journal of Cleaner Production, vol. 17, no. 5, pp. 541-548, 2009.

[44] L. Gangadharan and M. R. Valenzuela, "Interrelationships between income, health and the environment: extending the environmental Kuznets curve hypothesis," Ecological Economics, vol. 36, no. 3, pp. 513-531, 2001.

[45] F. Berkes, C. Folke, and J. Colding, Linking Social and Ecological Systems: Management Practices and Social Mechanisms for Building Resilience, Cambridge University Press, Cambridge, UK, 1998.

[46] U. Al-Mulali and I. Ozturk, "The effect of energy consumption, urbanization, trade openness, industrial output, and the political stability on the environmental degradation in the MENA (Middle East and North African) region," Energy, vol. 84, pp. 382-389, 2015.

[47] L. Charfeddine and Z. Mrabet, "The impact of economic development and social-political factors on ecological footprint: a panel data analysis for 15 MENA countries," Renewable and Sustainable Energy Reviews, vol. 76, pp. 138-154, 2017.

[48] G. C. Rodrigo Goyannes, D. Raquel de Freitas, M. L. Veiga, G. Q. Osvaldo Luiz, and L. F. Waler, "Towards sustainable development through the perspective of eco-efficiency - a systematic literature review," Journal of Cleaner Production, vol. 165, pp. 890-904, 2017.

[49] M. Song, J. Peng, J. Wang, and J. Zhao, "Environmental efficiency and economic growth of China: a Ray slack-based model analysis," European Journal of Operational Research, vol. 269, no. 1, pp. 51-63, 2018.

[50] Q. Zhou, X. Zhang, Q. Shao, and X. Wang, "The non-linear effect of environmental regulation on haze pollution: empirical evidence for 277 Chinese cities during 2002-2010," Journal of Environmental Management, vol. 248, no. 4, Article ID 109274, 2019.

[51] B. Frank and W. Marcus, "Assessing the relationship between economic and ecological performance: distinguishing system levels and the role of innovation," Ecological Economics, vol. 68, no. 7, pp. 1908-1914, 2009.

[52] S. Chen, "Environmental pollution emissions, regional productivity growth and ecological economic development in China," China Economic Review, vol. 35, pp. 171-182, 2015.

[53] J. Scheffran and B. Hannon, "From complex conflicts to stable cooperation: cases in environment and security," Complexity, vol. 13, no. 2, pp. 1257-1271, 2007.

[54] R. Rajesh, "Social and environmental risk management in resilient supply chains: a periodical study by the Grey-Verhulst model," International Journal of Production Research, vol. 57, no. 11, pp. 3748-3765, 2019.

[55] H. Yamashita, "The problems with a 'fact'-focused approach in environmental communication: the case of environmental risk information about tidal flat developments in Japan," Environmental Education Research, vol. 21, no. 4, pp. 586-611, 2015.

[56] T. Nakazawa, "Conflicting views on opposition to LULUs: distributive justice in three Japanese cases of waste disposal facility siting," Local Environment, vol. 23, no. 8, pp. 846-860, 2018.

[57] R. Kirkman and N. Voulvoulis, "The role of public communication in decision making for waste management infrastructure," Journal of Environmental Management, vol. 203, pp. 640-647, 2017.

[58] P. D. Wright, "Public engagement with large scale renewable energy technologies: breaking the cycle of NIMBYism," WIRES. Clim. Change, vol. 2, no. 1, pp. 19-26, 2011.

[59] D. Friedman, "Evolutionary games in economics," Econometrica, vol. 59, no. 3, pp. 637-666, 1991.

[60] Y. Adeyeye, S. Hagerman, and R. Pelai, "Seeking procedural equity in global environmental governance: indigenous participation and knowledge politics in forest and landscape restoration debates at the 2016 World Conservation Congress," Forest Policy and Economics, vol. 109, Article ID 102006, 2019.

[61] L. Marten Alex, "Garbaccio richard, wolverton ann, "exploring the general equilibrium costs of sector-specific environmental regulations," Environmental and Resource Economics, vol. 6, pp. 879-918, 2019.

[62] R. Wang, T. Zhou, D. Hu, F. Li, and J. Liu, "Cultivating ecosustainability: social-economic-natural complex ecosystem case studies in China," Ecological Complexity, vol. 8, no. 4, pp. 273-283, 2011.

[63] E. Cui, L. Ren, and H. Sun, "Evaluation of variations and affecting factors of eco-environmental quality during urbanization," Environmental Science and Pollution Research, vol. 22, no. 5, pp. 3958-3968, 2015.

[64] Y. Guo, X. Xia, S. Zhang, and D. Zhang, "Environmental regulation, government R\&D funding and green technology innovation: evidence from China provincial data," Sustainability, vol. 10, no. 4, pp. 940-952, 2018.

[65] D. Waymer, "Democracy and government public relations: expanding the scope of"Relationship" in public relations 
research," Public Relations Review, vol. 39, no. 4, pp. 320-331, 2013.

[66] D. Chong and N. Sun, "Explore emission reduction strategy and evolutionary mechanism under central environmental protection inspection system for multi-agent based on evolutionary game theory," Computer Communications, vol. 156, pp. 77-90, 2020.

[67] A. B. Da Silva Rocha and G. Meyer Salomão, "Environmental policy regulation and corporate compliance in evolutionary game models with well-mixed and structured populations," European Journal of Operational Research, vol. 279, no. 2, pp. 486-501, 2019.

[68] T. Sakai, "Fair waste pricing: an axiomatic analysis to the NIMBY problem," Economic Theory, vol. 50, no. 2, pp. 499-521, 2012.

[69] L. Tang, J. Li, L. Yu, and D. Qin, "Quantitative evaluation methodology for system coordination development based on distance coordination degree model," Syst. Eng. Theor. Pract.vol. 30, no. 4, pp. 594-602, 2010.

[70] I. Dattner, H. Ship, and E. O. Voit, "Separable nonlinear leastsquares parameter estimation for complex dynamic systems," Complexity, vol. 2020, Article ID 6403641, 11 pages, 2020.

[71] J. G. Wu and J. L. David, "A spatially explicit hierarchical approach to modeling complex ecological systems: theory and applications," Ecological Modelling, vol. 153, no. 1-2, pp. 7-26, 2002.

[72] R. Kaplan, "Public places and spaces human behavior and environment: advances in theory and research," Journal of Environmental Psychology, vol. 10, no. 3, pp. 290-292, 1990.

[73] N. Wiener, Cybernetics or control and communication in the animal and the machine, p. 32, MIT Press, Cambridge, MA, USA, 1961.

[74] O. Bina and S. G. Vaz, "Humans, environment and economies: from vicious relationships to virtuous responsibility," Ecological Economics, vol. 72, pp. 170-178, 2011.

[75] X. Li and Z. Zhang, "Research on local government governance and enterprise social responsibility behaviors under the perspective of Cournot duopoly competition: analyzing taxi companies and online Car-Hailing service companies," Mathematical Problems in Engineering, vol. 2018, pp. 1-12, Article ID 5794232, 2018.

[76] Z. Mu, S. Bu, and B. Xue, "Environmental legislation in China: achievements, challenges and trends," Sustainability, vol. 6, no. 12, pp. 8967-8979, 2014. 